Revista lus et Praxis, Año 21, № 2, 2015, pp. 161 - 198

ISSN 0717 - 2877

Universidad de Talca - Facultad de Ciencias Jurídicas y Sociales

Motivo de casación en el fondo civil en Chile. Problemas y perspectivas de reforma

Carlos del Río Ferretti

Trabajo recibido el 27 de noviembre de 2014 y aprobado el 20 de mayo de 2015

\title{
Motivo de casación en el fondo civil en Chile. Problemas y perspectivas de reforma*
}

\author{
"The cassation cause In the ChILEAN CIVIL CORE. \\ PROBLEMS AND REFORM PERSPECTIVES"
}

Carlos del Río FerRetTi**

\section{RESUMEN}

Este estudio está dedicado al análisis del motivo del recurso de casación, puesto que siendo una cuestión esencial en la configuración legal del recurso, en nuestro Ordenamiento jurídico, no obstante, existen indefiniciones y en la práctica forense persisten dudas sobre distintos aspectos vinculados a esta materia, respecto de los cuales se cuenta con pocos estudios dogmáticos destinados a su aclaración. El artículo contribuye con una reflexión orientada, primero, a indagar sobre la amplitud de la infracción normativa que pueda ser censurada por este medio de impugnación, actualmente abarcada con la expresión contenida en el art. 767 del Código de Procedimiento Civil sobre la «infracción de ley». En segundo término, el análisis pretende avanzar apuntes sobre los aspectos que ameritarían un estudio para su reformulación con ocasión de una futura reforma al proceso civil entero, y cómo la actual propuesta de reforma -en tramitación legislativa- podría llegar a incidir en el asunto de la configuración del o de los motivos del recurso que vendría a tomar el lugar de la casación (el recurso extraordinario).

ABSTRACT

This article is dedicated to the analysis of the cassation recourse cause, since, although it is an essential question in the legal configuration of the recourse, there is a lack of definitions in our legislation, and in the forensic practice there persist doubts relative to different aspects linked to this matter. In addition, there are few dogmatic studies published to help in their clarification. The article contributes with an oriented reflection, first, to enquire about the vastness of the normative infraction that might be censured by this means of impeachment. Currently this is addressed with the expression contained in art. 767 of the Civil Procedural Code about "violation of law". In second terms, the analysis pretends to progress on the notes about those aspects that would justify a study for its reformulation given a future reform to the entire civil procedure, and

* Estudio que hace parte del Proyecto FONDECYT REGULAR No 1131129, cuyo investigador responsable es el autor. Se deja constancia del mismo modo que el texto fue concluido durante la estancia de investigación que realizara en la Facultad de Derecho de la Universidad de Valencia en el marco del Proyecto indicado. Agradezco al distinguido profesor Dr. Manuel OrTells Ramos su gentil invitación para visitar el prestigioso departamento de Derecho Procesal de Valencia, tanto como sus comentarios y observaciones a este trabajo.

** Doctor en Derecho por la Universidad de Valencia. Profesor de Derecho procesal de la Universidad Católica del Norte. Dirección postal Calle Larrondo 1281, Coquimbo (Campus Guayacán UCN). Correo electrónico: cdrio@ucn.cl 
how the current reform proposal -undergoing legislative processing-could come to impact in the issue of configuration of the recourse motives that would take place instead of cassation (the extraordinary recourse).

Palabras Clave

Motivo de casación, Infracción de ley, Infracción de norma constitucional, Infracción de norma infralegal, Infracción de normas reguladoras de la prueba, Reforma procesal civil

KEY WORDS

Cassation cause, Violation of law, Violation of constitutional norm, Violation of infra-legal norm, Proof regulatory norm violation, Civil procedural reform

\section{Introducción: el motivo del recurso de casación como una cuestión clásica en su configuración legal, y no obstante todavía problemática en nuestro Derecho. La denominada infracción de ley}

Con seguridad una de las cuestiones clásicas con relación al régimen casacional es la referida al motivo del recurso, lo cual tiene además la calidad de esencial atendida la naturaleza del recurso en cuestión: el objeto abstracto del recurso de casación viene determinado por el motivo. De allí es que el estudio y escrutinio dogmático de este aspecto de su régimen resulte decisivo.

Lo esperable entonces sería encontrarse con profusos análisis doctrinales y una nutrida jurisprudencia que hubiese llevado el estudio de la configuración del motivo a unas cotas en donde la discusión a su respecto ya hubiese agotado los problemas más manifiestos o relevantes, limitando con ello el debate plausible a matices específicos sobre puntos muy concretos acerca de la configuración del motivo del recurso. Sin embargo, no es esta la situación dogmático-jurisprudencial en nuestro medio, sino, al contrario, todavía persisten dudas e indefiniciones relevantes sobre este extremo.

La doctrina chilena ${ }^{1}$ trata del alcance o cobertura casacional por la vía de interpretar lo que se ha de entender por ley y por infracción de esta, lo cual viene naturalmente determinado por lo dispuesto en el art. 767 CPC, en tanto se ha considerado que allí se encuentra consagrado el motivo de casación en el fondo en nuestro proceso civil. En lo pertinente este precepto señala que "[e]l recurso de casación en el fondo tiene lugar contra sentencias (...), siempre que se hayan pronunciado con infracción de ley y esta infracción haya influido sustancialmente en lo dispositivo de la sentencia". Preliminarmente un precepto como el indicado podría sugerir una cierta limitación a las posibilidades interpretativas, especialmente si se tiende a suscribir un concepto estricto y formal de ley, en cuyo caso se arribaría a la conclusión de que la infracción relevante es la de la ley, y con ello se inferiría así mismo que quedan excluidas todas las demás

\footnotetext{
1 Espinosa (s/f), pp. 165 y ss.; Fernández (2000), pp. 153-154; Paillás (2008), pp. 61-93; Romero, AgulRREZÁbal y Baraona (2008), pp. 248 y 259; Mosquera y Maturana (2010), pp. 295 y ss.
} 
normas no legales. Con todo, la opinión dominante y mayoritaria introdujo matizaciones importantes a la interpretación del precepto en cuestión y que de forma sintética se puede condensar en la idea que el concepto de ley no debía venir determinado por la concepción formal estricta de tal, sino más bien habría de referirse a un concepto material abarcador de toda norma jurídica a la que se le reconociese naturaleza o rango legal y que se integrase en un concepto más amplio de ley. Esta forma de entender el asunto no recibió un tratamiento acabado y sistemático, sino más bien se solía invocar como una forma de dar entrada al control casacional a normas jurídicas de origen no legislativo pero de rango legal, como es el caso de los Decretos Leyes o de los Decretos con Fuerza de Ley, o como un medio para afirmar de manera general la cobertura de los tratados internacionales o de la Constitución.

Algunos autores ${ }^{2}$, sin embargo, han buscado una vía distinta a la de la interpretación del art. 767 CPC, al auspiciar una presunta superación de la causal prevista en aquel precepto, desde que se verificara la reforma de la Ley $N^{0} 19.374$ y que vino a modificar-entre otros- el art. 772. En esa norma reformada se eliminó la necesidad de singularizar el precepto legal infringido, y se dispuso en su lugar el requisito de indicar el error de Derecho que se habría producido en la sentencia, lo cual ha sido interpretado no tan solo como una modificación de los requisitos de interposición del recurso, sino como una norma que incidiría en la configuración de la causal misma de casación. Esta vendría a prevalecer sobre la previsión del art. 767, con la que se encontraría en una relación antinómica: así la norma legal posterior producía la derogación tácita del precepto legal anterior. De esta manera haciendo prevalecer el art. 772 reformado se sugería que la referencia a la necesidad de determinar el error de Derecho, y no la precisa ley infringida, tenía como efecto que el motivo abarcaba la infracción de cualquier norma jurídica, y no tan solo la de la ley o de aquellas de rango legal.

El argumento interpretativo precedente tuvo una finalidad razonable, como era la búsqueda de espacios para dar entrada a la casación a «fuentes del Derecho» distintas de la ley. El cauce para ese propósito era de esta manera generoso, pues no quedaba atado de ninguna manera al precepto del art. 767 CPC, y con ello el camino quedaba despejado para llegar a afirmar que la infracción de cualquier norma jurídica tenía trascendencia casacional, inclusive con independencia de si ella formaba parte del Derecho positivo en su sentido más estricto, vale decir, con independencia de si se trata de normas jurídicas dadas (emanadas) formalmente (escritas) por una autoridad con potestad normativa.

2 Romero et al. (2008), pp. 248 y 259. 
No nos parece, sin embargo, acertada esa forma de interpretación de los preceptos indicados, puesto que el art. 772 CPC no contenía, ni contiene tampoco -tras la reforma- el motivo del recurso. El establecimiento de la norma que dispone que «(e)l escrito en que se deduzca el recurso de casación deberá 1) (e)xpresar en qué consiste el o los errores de derecho de que adolece la sentencia recurrida, y 2) (s)eñalar de qué modo ese o esos errores de derecho influyen sustancialmente en lo dispositivo del fallo», no tuvo por finalidad sino únicamente atenuar el rigor formal ${ }^{3}$ con el que se habían interpretado los requisitos de interposición del recurso, de manera que la falta de mención precisa de un precepto infringido (o de todos y cada uno de ellos) y la falta de acierto exacto sobre el tipo de infracción llegaran a embarazar la admisibilidad o estimación de fondo del recurso, cuestión que obviamente parecía un exceso atendido la indudable aplicación del principio de iura novit curia. La interpretación judicial restrictiva fue la que primó hasta la modificación indicada, ya que hasta ese momento encontraba asidero por lo demás en la redacción precedente del artículo 772 CPC, que justamente indicaba que el escrito de interposición del recurso debía hacer "mención expresa y determinada de la ley o leyes que se supongan infringidas, de la forma en que se ha producido la infracción y de la manera como ésta influye en lo dispositivo del fallo". Así, la modificación de estos requisitos de interposición en el art. 772 supuso en consecuencia una relajación normativa en cuanto al cumplimiento de aquellos, pero en caso alguno una reformulación del motivo del recurso que seguía estando previsto en el art. 767.

En efecto, en nuestra opinión, el camino interpretativo rigurosamente exacto parte con el ineludible reconocimiento que la determinación de la amplitud tiene que estar vinculada al art. 767 CPC. Ciertamente una redacción distinta de este, que en lugar de referirse a "la infracción de ley" aludiera a la "infracción de una norma de Derecho" permitiría una superación clara de la interpretación restrictiva, amparada en el contenido gramatical del precepto. Con todo, la falta de una redacción así de deseable no constituye un impedimento insalvable para propiciar una interpretación más armónica con las finalidades del recurso de casación (la defensa del Derecho objetivo y la unificación de jurisprudencia). Y la razón para sostener una cosa como esta es que -en la línea interpretativa expuesta al inicio- el legislador no utiliza en un único sentido el concepto de ley. Desde luego, a veces refiere el término como sinónimo de "legislación", comprendiendo con ello a otras fuentes normativas. Con todo, el argumento anterior sobre el carácter ambiguo de la voz ley no es la clave de la solución -como se suele esgrimir-, sino más bien un indicio. Aquella clave en realidad

${ }_{3}$ Por todos, MuÑoz (2008), p. 54. 
se encuentra en lo que hace años apuntara Carnelutti ${ }^{4}$, cuando reconocía que el Código de Procedimiento Civil italiano de 1940, al haber modificado la fórmula del motivo de casación por error de fondo, puso de manifiesto que lo que se constituía en relevante a efectos de la denuncia de infracción por esta vía no era una determinada calidad de la fuente normativa que se invocara, sino la calidad del mandato que emanaba de ella. Así, el autor indicado señalaba que el Código italiano de 1940, superando en este punto a la legislación precedente, ya no aludía a una fuente determinada sino al carácter de norma del mandato. Sostenía que un mandato se constituye en norma en la medida que posea el carácter de general, lo que resulta ser independiente de la fuente formal en que se halle contenido. De este modo -explicaba- quedan excluidos de esta categoría aquellos mandatos particulares o concretos. Y añadía que con esta forma de enfoque podía concluirse, por ejemplo, que la infracción de un precepto legal -de la ley formal-no resulta simple y automáticamente relevante a efectos de recurso de casación, puesto que puede ser perfectamente posible que la ley formal contenga un mandato particular (que denomina ley impropia) y, siendo de esta manera, concluía que en ese supuesto debía excluirse la denuncia de infracción de una ley de esta especie por la vía del recurso de casación. Desde esta perspectiva el punto decisivo estriba entonces en determinar si se trata de una norma positiva, entendida esta como mandato jurídico de carácter general ${ }^{5}$, en lugar de quedarse entrampado en la concepción gramatical de la fórmula legal, haciendo caso omiso de la comprensión científica pertinente y armónica con los mismos fines que se reconocen al instituto de la casación actualmente.

Con las aclaraciones y precisiones anteriores resulta menester hacer un escrutinio sobre la discusión respecto de las hipótesis que quedarían comprendidas dentro del motivo del art. 767.

\section{La infracción de norma constitucional}

En el trabajo de determinación de la amplitud del motivo de casación en el fondo, una parte de la doctrina -al considerar la cobertura ofrecida por el concepto de infracción de ley- ha mantenido sin duda ${ }^{6}$ que la infracción de un precepto constitucional resulta perfectamente denunciable por la vía del recurso de casación en el fondo. Esta aseveración en principio no plantea objeciones teóricas si al texto constitucional se le reconoce valor normativo y al

\footnotetext{
${ }^{4}$ Carnelutti (1959), pp. 259-261. También Nappi (2006), pp. 78-79; Boré (1988), pp. 371 y ss. y p. 572; Couchez y Lagarde (2014), p. 483; Morón Palomino (2001), p. 156.

${ }^{5}$ Con detalles y matices, NAPPI (2006), pp. 78-79.

${ }^{6}$ Véase, por todos Romero, Aguirrezábal y Baraona (2008), pp. 236-237.
} 
mismo tiempo se estima posible su aplicación directa ${ }^{7}$. Dado lo anterior, como mínimo habría que convenir que es denunciable en casación una infracción de precepto constitucional cuando este tiene el carácter de regulatorio de una situación jurídica interpartes y acaba siendo el precepto aplicable al caso concreto. Ciertamente también es posible la denuncia de infracción de un precepto constitucional cuando este aparece conjuntamente infringido con un precepto legal, en cuyo caso podríamos decir que la infracción constitucional se cita como una forma de recalcar la ilegitimidad jurídica de la sentencia recurrida.

Con todo, un asunto que no siempre se considera es aquel de cuánto relieve puede tener la Constitución como norma directamente aplicable, cuando en el caso chileno la misma adolece de una manifiesta falta de densidad normativa y de calidad técnico-jurídica, rasgos muy acusados en el texto constitucional chileno, de modo que en pocos casos la Constitución contiene mandatos jurídicos que operen como normas decisorias de la litis en el Derecho civil (o no criminal en general). Así podría afirmarse que la infracción de norma constitucional, si bien teóricamente está comprendida en la fórmula del motivo del art. 767, tiene una trascendencia práctica limitada.

\subsection{La denuncia en casación de la infracción de un precepto constitucional cuando el juez aplica una norma legal presuntamente inconstitucional}

De acuerdo a lo expuesto cabe plantearse un segundo supuesto (distinto del anterior) que presenta dificultades, como es el tocante a la denuncia de infracción de un precepto constitucional cuando el juez decide aplicar un precepto legal presuntamente inconstitucional ${ }^{8}$. ¿Podría invocarse la infracción de una norma constitucional a causa de que el juez ha decidido aplicar una norma legal, si se entiende que el juez se halla sometido a la ley? La respuesta de Mosquera y Maturana ${ }^{9}$, como de Zúñiga ${ }^{10}$ y Atria ${ }^{11}$, es negativa, puesto que esgrimen que el juez al aplicar la ley -aun inconstitucional- lo que hace es obedecer o cumplir con un deber de sumisión y de aplicación de aquella, y no puede -a pretexto de dar aplicación directa a la norma constitucional- preterir la aplicación de una norma legal, puesto que por esa vía se acaba desconociendo el monopolio del control de constitucionalidad. En una posición opuesta se ha manifestado Fernández ${ }^{12}$, quien es partidario de la relevancia casacional en este caso de la

\footnotetext{
7 Fernández (1993), pp. 55 y ss.; (2001), pp. 77 y ss.; y (2005), pp. 97 y ss.

${ }^{8}$ Mosquera y Maturana (2010), pp. 295-296.

9 Mosquera y Maturana (2010), pp. 295-296.

10 ZÚNIGA (2005), pp. 15 y ss.

11 AtriA (2005), pp. 284-285.

12 Fernández (1993), pp. 55 y ss.; (2001), pp. 77 y ss; y (2005), pp. 97 y ss.
} 
infracción de normas constitucionales con base esencialmente en el carácter jurídico vinculante y de aplicación directa de la norma constitucional, derivados del artículo $6^{\circ}$ de la Constitución.

Con todo, un enfoque exacto del asunto exige que al argumento de la sumisión a la ley de los jueces se añada una puntualización relevante, consistente en apuntar que el deber de sumisión es a aquella ley (rectius, Derecho) que sea constitucionalmente legítima -al menos si creemos en el principio de supremacía constitucional-, con lo cual ese sometimiento no debe entenderse como automático e irreflexivo, que impida la reacción frente a la inconstitucionalidad de un precepto legal.

Precisamente con respecto a la duda formulada, cabe reconocer en primer lugar que siempre corresponde a la CS el poder de interpretar la ley y en esa función interpretativa promover interpretaciones conformes con la Constitución, con lo cual, visto el asunto desde la perspectiva de la casación no puede desconocerse que sea perfectamente denunciable y censurable una interpretación de la ley disconforme con la Constitución (con una norma constitucional). La CS entonces dentro de este marco puede y debe ejercer su poder casacional censurando interpretaciones legales disconformes con la norma constitucional, fijando al tiempo la interpretación legal conforme con aquella, siempre sin rebasar los márgenes que le corresponde en su función hermenéutica de la ley. Nótese sin embargo que este cauce debe partir del reconocimiento de que se censura una interpretación de la ley en contraste con la Constitución.

Hecha la matización anterior la hipótesis que se enuncia es distinta de la denuncia y censura de una interpretación legal disconforme con la Constitución. Ahora se trata de la denuncia de una infracción de norma constitucional precisamente por la aplicación de una norma legal presuntamente inconstitucional. Obviamente, esta hipótesis problemática desde el punto de vista de su cobertura casacional, solo tiene sentido planteársela si se entiende que el problema concreto - de carácter normativo- no encuentra solución por vía interpretativa de la propia norma legal, de modo que en la especie se presenta una falta de adecuación normativa estricta de la ley a la Constitución, insuperable por aquella vía.

Dado este supuesto la pregunta inicial tiene más precisión: puede denunciarse en casación la infracción de norma constitucional cuando el juez ha decidido aplicar un precepto legal inconstitucional. En nuestro concepto la respuesta práctica ha de ser positiva, existiendo para ello dos fundamentos de respaldo claros. En efecto, el primero estriba en el reconocimiento del carácter normativo de la Constitución: esta es una norma jurídica y no una «norma programática», de modo que en esa condición hace parte del Derecho objetivo que es menester tutelar o proteger por medio de la casación. El segundo fundamento radica a su turno en que una denuncia de este tipo resulta imposible de distinguir en abstracto con los supuestos anteriores referidos a la 
interpretación legal conforme o bien al caso de la falta o incorrecta aplicación de la propia Constitución cuando sea esta la única norma aplicable al caso, y no se encuentre implicado entonces un precepto legal inconstitucional. Por lo demás una posición en contrario tampoco tiene sentido procesal alguno, puesto que la formulación de la denuncia podría perfectamente evitar la objeción de falta de cobertura casacional simplemente afirmando la infracción de norma constitucional o de incorrecta (disconforme) interpretación de ley, omitiendo la denuncia en el recurso de la presunta inconstitucionalidad del precepto legal para que aquello no pueda ser en absoluto considerado una denuncia y pretensión recursiva inadecuadas.

Con todo, lo expuesto no implica pretender que por la vía del recurso de casación se pueda acabar promoviendo una suerte de control difuso de constitucionalidad realizado por la CS. Al contrario, como el deber de sometimiento es al Derecho (la ley) constitucionalmente legítimo ${ }^{13}$, el juez ordinario debe a su vez precaver -examinar de oficio ${ }^{14}$ - la eventual inconstitucionalidad y, en caso de estimarla concurrente, utilizar el mecanismo jurídico previsto en ese caso, como es el planteamiento de la cuestión de inaplicabilidad por inconstitucionalidad $^{15}$. Este es un poder-deber y no una potestad facultativa ${ }^{16}$, conclusión que entendemos se deriva de lo dispuesto en el art. 93 inciso duodécimo de la Constitución y en los arts. 3, 44 y 79 de la LOTC, aun cuando todos esos preceptos no establezcan de forma concluyente que se trata de una potestad de ejercicio necesario, como, por ejemplo, sí se establece de forma clara en el Ordenamiento español, según lo disponen los arts. 163 CE y 5 LOPJ ${ }^{17}$. En otro caso - de no considerarse sino una potestad facultativa- se arribaría al absurdo de que advertida una inconstitucionalidad por el juzgador, este pueda decidir si se somete al principio de supremacía constitucional y formula la cuestión

\footnotetext{
13 Véase, Montero Aroca (2000), pp. 115-117.

${ }^{14}$ En el sistema de control de constitucionalidad de las leyes y específicamente en la inaplicabilidad por inconstitucionalidad, en el modelo chileno se le reconoce legitimación activa a las partes del proceso pendiente, quienes pueden formular el requerimiento directamente ante el Tribunal Constitucional, ello sin perjuicio del examen de oficio que deba hacer todo juez ordinario en los asuntos que se le someten. Esta es una diferencia neta con otros sistemas como, por ejemplo, el modelo italiano, en donde las partes solo pueden pedir la formulación de la cuestión de inconstitucionalidad al juez ordinario que sustancia el proceso, quien decide si remite la cuestión al control de constitucionalidad solicitado, tal como lo prevé el art. 23 de la Ley 87/1953. Obviamente, también tiene el poder de oficio para plantearlo él mismo si considera concurrente una cuestión de inconstitucionalidad. Véase, Belletti (2007), pp. 418 y ss.

15 Obra citada.

${ }^{16}$ Compartimos las opiniones de LeTeLIeR (2007), pp. 539-574.

17 En el caso alemán ocurriría algo semejante derivado de lo dispuesto en el art. $100.1^{\circ}$ de la Constitución alemana, véase WALter (2001), pp. 744-745.
} 
de inaplicabilidad o si, por el contrario, se inclina por aplicar en el caso aquel precepto ilegítimo ${ }^{18}$.

Ahora bien, entendida correctamente aquella potestad de promover la cuestión de inaplicabilidad como de ejercicio necesario, correlativamente habría que concluir que efectuado el escrutinio y desechada la inconstitucionalidad por el Tribunal Constitucional, el precepto legal ha de ser necesariamente aplicado, no pudiendo obviarse esto a pretexto de una presunta inconstitucionalidad.

\subsection{El caso de la derogación tácita de un precepto legal por la norma constitucional posterior: ¿Juicio de contradicción o juicio de adecuación?}

La tercera situación relacionada con lo expuesto es la que se formula en la tesis de la presunta derogación tácita de un precepto legal por una norma constitucional posterior y la posibilidad de plantear un asunto como este mediante el recurso de casación.

Sobre este punto resulta sumamente interesante la cuestión suscitada respecto de la posibilidad de hacer un examen de esta especie en situaciones en que se considera haberse producido una incorrecta determinación y aplicación de una norma legal que se estima derogada tácitamente por la Constitución, circunstancia a la cual se atribuye la connotación de infracción de una norma constitucional. ¿Puede en tal supuesto plantearse un recurso de casación ante la CS con el fin de que esta conozca y eventualmente declare (censure) una infracción de un precepto constitucional por haberse aplicado en la sentencia impugnada una norma legal tácitamente derogada por aquel? Tal es el asunto resuelto en la SCS de 28 de septiembre de 2010, rol 1018-2009, en donde se declaró que los artículos 15 y 16 del D.L. № 2.695 de 1979 habían sido derogados tácitamente por la Constitución de $1980^{19}$, ya que aquellos estarían en contradicción con su art. $19 \mathrm{~N}^{\circ} 24$, norma posterior, que consagra como derecho fundamental el derecho de propiedad, el cual al estar en contradicción con el D.L. № 2.695 (Normas para la regularización de la pequeña propiedad raíz y para la constitución del dominio sobre ella), especialmente con sus arts. 15 y 16, dichos preceptos quedarían tácitamente derogados. En el caso del primer precepto, la contradicción se concretaría porque en este se establece que mediante una resolución de autoridad administrativa se constituya en poseedor regular al peticionario, con independencia de que existan otras inscripciones de dominio precedentes. Con respecto al segundo precepto, la contradicción con el texto constitucional vendría dada por la previsión de un plazo brevísimo de un

\footnotetext{
18 Letelier (2007), pp. 539-574.

${ }^{19}$ Cuestión que ha sido discutida por la doctrina desde hace bastantes años. La derogación tácita en el caso que se expone fue defendida específicamente por FERNÁNDEZ (1993), pp. 55 y ss.
} 
año para la prescripción extintiva de las acciones que puedan tener terceros y especialmente el propietario del inmueble. Con el primer precepto se afectaría el dominio por la vía de una resolución administrativa. Con el segundo -mediante una prescripción de muy corto tiempo- se limita seriamente la posibilidad de impetrar tutela jurisdiccional, lo cual Ilega en concreto a afectar los atributos del dominio, al convertirlo en un derecho con una precaria tutela jurídica.

Como se ha dicho, el verdadero asunto relevante para nuestro análisis no es, no obstante, si las reflexiones jurídicas ofrecidas por la SCS son correctas, sino si le está permitido a la CS declarar en sentencia de casación que un precepto legal preconstitucional haya sido derogado tácitamente por la Constitución posterior, y acabar entonces censurando la infracción de un precepto constitucional.

Planteado el asunto en términos generales este merecería una respuesta negativa en la inmensa mayoría de supuestos imaginables, fundamentalmente de nuevo por la insalvable falta de densidad normativa del texto constitucional y la bajísima precisión técnica de aquel, cuestión que inicialmente excluye que un precepto legal pueda estar -normativamente hablando- en contradicción con un precepto constitucional (salvo que haya una norma constitucional que contenga un mandato jurídico regulatorio o claramente derogatorio $\left.{ }^{20}\right)$. Con todo, cabe reconocer que dicha posibilidad no puede negarse de forma general, cuando lo cierto es que siempre corresponde a la propia CS evaluar la densidad normativa como presupuesto necesario para poder formular un juicio de contradicción entre dos normas jurídicas (entre dos mandatos jurídicos en sentido propio), y que acabe derivando en una censura casacional por la aplicación de una norma legal derogada por una norma constitucional.

De este modo, el caso propuesto (del D.L. № 2.695) podría hacer surgir la duda sobre el extremo justamente porque el art. 19 № 24 de la Constitución escapa a esa constante mezquindad normativa del texto constitucional y en este caso va más allá de la pura enunciación de principios ambiguos, y se anima a consagrar garantías sustanciales del mismo derecho fundamental de propiedad, que sin duda operan como condiciones materiales para las fuentes formales de rango inferior. En este supuesto podría parecer plausible plantearse una derogación tácita de normas legales previas que aparezcan en «contradicción» con la norma constitucional posterior. Una idea como la indicada resulta razonable, pero lo cierto es que en este caso la respuesta ha de ser negativa. Y esto es así, puesto que para que una norma sea derogada tácitamente por otra posterior ha

${ }^{20}$ Nótese que en Chile no existe una norma que derogue expresamente los preceptos legales anteriores a la Constitución, salvo lo que limitadamente establece la disposición Cuarta Transitoria de la Constitución. Tampoco contiene una norma o cláusula general derogatoria por medio de la cual se deroguen tácitamente todos los preceptos legales contrarios a la Constitución, como sí acontece con la Constitución española o con la alemana art. 123.1. 
de estar efectivamente en «contradicción» con esta. Y para declararlo de este modo habrá de tratarse de normativas referidas a una misma materia, de suerte que realmente se pueda predicar la existencia de mandatos opuestos entre la anterior regulación legal y la posterior regulación constitucional, y se pueda concluir entonces que la primera ha de quedar lógicamente excluida por esta. Así, para que haya "contradicción» debe ser posible inferir de forma indubitada el mandato jurídico y, en consecuencia, el efecto de la norma posterior de privar de vigor o vigencia a la norma antecedente sobre la materia. Lo dicho no obstante no concurre en el caso referido, puesto que -como se ha dichoun presupuesto esencial es que las normas estén estableciendo una regulación incompatible sobre una misma materia, y lo cierto es que el art. $19 \mathrm{~N}^{\circ} 24$ de la Constitución establece y regula el derecho fundamental de propiedad y sus garantías, pero al mismo tiempo entrega al legislador el tratamiento de las otras materias - por el contrario, ordinarias- referidas al modo de adquirir, de usar y disponer de los bienes y las referidas a limitaciones y obligaciones que derivan de su función social, con lo cual la norma constitucional opera en el ámbito del establecimiento y determinación de contenido de un derecho fundamental, mientras que la ley (el D.L. № 2.695) configura las materias de regulación ordinaria del derecho subjetivo del modo ya indicado, de manera que no son normas sobre un mismo objeto y por eso su relación no puede ser exactamente de "contradicción" y, por lo tanto, de exclusión. La relación entre estas normas es de "adecuación" y "condicionamiento" (a raíz del principio de supremacía constitucional), en donde la norma infraconstitucional (la ley) en la regulación de las materias que le son propias debe adecuarse a los condicionamientos constitucionales, cuestión que ya no se refiere a su vigencia sino derechamente a su validez o legitimidad constitucional. Y es precisamente esto lo que se controla por medio del juicio de constitucionalidad de las leyes: un juicio de adecuación de la ley a la norma constitucional supraordenada que marca los límites al legislador sobre el ámbito legítimo de configuración normativo-legal.

Por las razones indicadas, cuando la SCS de 28 de septiembre de 2010, rol 1018-2009, mediante el conocimiento de un recurso de casación en el fondo declara la derogación tácita de los preceptos legales del D.L. № 2.695 de 1979 por haber sido derogados con la entrada en vigor de la Constitución, y por esa vía declara la infracción de varios preceptos constitucionales y especialmente el del art. $19 \mathrm{~N}^{\circ} 24$, lo que en realidad está realizando es un juicio negativo de adecuación de los preceptos legales a la norma constitucional, propio de un control de constitucionalidad que en nuestro sistema de jurisdicción constitucional concentrado pertenece exclusivamente al Tribunal Constitucional ${ }^{21}$. Este

${ }^{21}$ Como hemos apuntado con anterioridad, cierta doctrina constitucional ha avalado la aproximación (sino la confusión) de la derogación tácita de la ley y su control casacional y el control de constitu- 
es un caso típico en donde si el juez estimaba una eventual inconstitucionalidad sobrevenida, en lugar de precipitarse a hacer el control de constitucionalidad de ley por su cuenta o, por el contrario, de resignarse sin más a la aplicación del precepto legal aparentemente inconstitucional, pero vigente, debía plantear la necesaria cuestión de inaplicabilidad por inconstitucionalidad consagrada en el artículo $93 \mathrm{~N}^{\circ} 6$ de la Constitución.

\section{La infracción de normas jurídicas infralegales}

Para seguir con el análisis tocante a la cobertura dada por el motivo del recurso de casación (art. 767) también corresponde plantearse el problema de la infracción de las normas jurídicas infralegales y su inclusión en aquel. Lo cierto es que la opinión de la doctrina chilena frecuentemente partidaria de la relevancia casacional de la infracción de la norma constitucional, no obstante el limitado rendimiento práctico, contrasta con la casi unanimidad existente en orden a no discutir y dar por buena la doctrina que niega sin matices la posibilidad de denunciar la infracción de normas infralegales. En efecto, Ilama la atención el entusiasmo con que la doctrina suele apoyar la afirmación generalista de la relevancia casacional de la infracción de "normas" constitucionales cuando la utilidad práctica es cuantitativamente escasa, mientras paralelamente pasa "de puntillas" con un análisis escueto sobre el conjunto de normas jurídicas que contienen auténticos mandatos generales y abstractos aplicables para la solución de casos concretos, pero que son sin embargo normas jurídicas infralegales. Así se descarta que la casación sea procedente por infracción de una norma reglamentaria, de un decreto supremo o de otra norma jurídica infralegal ${ }^{22}$.

Los autores que se han ocupado de la determinación de la cobertura casacional $^{23}$, en términos generales apuntan de manera invariable que la jurisprudencia de la CS le ha negado la "calidad de ley" a los decretos supremos, a los reglamentos, a los dictámenes de la Contraloría y a las circulares administrativas, y concluyen que con ello ha querido establecerse de manera clara que todas estas normas no tienen acceso a la casación, esto es, su infracción no resulta denunciable por esta vía recursiva. La doctrina ha avalado sin matices la posi-

cionalidad de la ley, lo que de algún modo el profesor Fernández (2001), pp. 97 y ss, entendía que se justificaba por la falta de un mecanismo que conciliaría la eficacia normativa de la constitución y el control concentrado de constitucionalidad de las leyes, en los términos en que por ejemplo sí se resuelve en Derecho español, con los arts. 163 CE y 5 LOPJ. En nuestra opinión una justificación de esta especie desde la reforma de 2005 ya no es procedente, en tanto estimamos que en nuestro Derecho, a partir de aquella época, existe el mismo mecanismo que echa en falta el autor citado y que permite superar la pugna de principios e intereses.

22 Ha manifestado sus dudas sobre este punto MuÑoz (2010), pp. 142-143

${ }^{23}$ Espinosa (s/f), pp. 172-173; Fernández (2000), pp. 153-154; Romero et al. (2008), p. 231; Mosquera y Maturana (2010), p. 298. 
ción de la jurisprudencia, consistente en considerar que el artículo 767 del CPC hace referencia a la infracción de ley y, por extensión, a todas aquellas fuentes con rango de ley, vale decir, ubicadas en el mismo nivel normativo, y entonces contrario sensu aquello excluiría la relevancia casacional de las infracciones de todas las fuentes de rango infralegal.

$\mathrm{Al}$ respecto -tal como señalamos al principio- desde hace tiempo ${ }^{24}$ el procesalismo extranjero puso de manifiesto que lo que se constituía en relevante a efectos de la denuncia de infracción por esta vía no era una determinada calidad de la fuente que se invocara, sino la calidad del mandato que emanaba de ella ${ }^{25}$. Por otra parte se apuntaba ${ }^{26}$ lo que con posterioridad vino a quedar como algo indiscutido, en el sentido que puedan emanar normas de Derecho relevantes a efectos de cobertura casacional de la potestad administrativa.

En Derecho francés los criterios en vigor son semejantes a los indicados, en tanto no cabe duda que el concepto de ley se utiliza en su acepción material, vale decir, refiriéndolo a la norma general y abstracta, y por eso mismo no se discute que ella pueda abarcar otras fuentes normativas que reúnan esas características aunque no sean desde luego ley en su sentido formal, e incluso posean un rango normativo infralegal ${ }^{27}$.

En el último tiempo, Nappi ${ }^{28}$ ha singularizado los criterios decisivos para determinar lo que ha de entenderse por norma de Derecho, y al respecto ha dicho:

"Son tres las condiciones de utilizabilidad de un criterio de cualificación como motivo de recurso en los sentidos del art. 360.1, n. 3, срс o del art. 606.1, letra b, сpp".

«a) la universabilidad;»

«b) la juridicidad;»

«c) la sustancialidad, en el sentido de pertenencia al derecho material antes que procesal.»

Este autor ${ }^{29}$ considera que el criterio de universabilidad supone que aquel esté referido a clases de sujetos, "previniendo discriminaciones», tanto como a clases de acciones, para favorecer «la certeza de las calificaciones». Así, la universabilidad de la norma permite que de ella se desprenda un criterio de

${ }^{24}$ Carnelutti (1959), t. II, pp. 259-261.

25 Carnelutti (1959), t. II, p. 259. También Nappi (2006), p. 77.

${ }^{26}$ Carnelutti (1959), t. II, p. 260.

27 Boré (1988), pp. 371 y ss. y 572 y ss.; Jobard-Chevallier y Chevallier (2006), pp. 51 y ss.; Couchez y LAGARDE (2014), p. 483.

${ }^{28}$ NAPPI (2006), p. 78.

${ }_{29}$ NAPPI (2006), pp. 78-79. 
enjuiciamiento aplicable a casos semejantes, que es lo realmente relevante a efectos de determinar la cobertura casacional de una norma, y por esta razón se descarta que una regla que sirva de criterio de enjuiciamiento derivada de un contrato pueda quedar cubierta por el motivo de casación, puesto que no se trata de un criterio universalizable, en tanto únicamente es útil como tal respecto de la relación contractual a que está referido.

$\mathrm{Nappi}^{30}$ reconoce la naturaleza de norma con este carácter de universabilidad a los reglamentos administrativos siempre que posean una función normativa. Se atribuye dicha función a aquella reglamentación administrativa que «especifica» o «integra» la regulación contenida en la legislación «con efectos no circunscritos a los sujetos de una particular categoría».

En nuestra opinión no debiera ser discutible en el Derecho chileno la relevancia casacional de las normas infralegales provenientes de la potestad reglamentaria, en cuanto las mismas contengan mandatos jurídicos universalizables capaces de funcionar como criterios normativos decisorios de la cuestión de fondo planteada ${ }^{31}$.

Ciertamente en nuestro Derecho tenemos casos en las materias laboral y civil, en donde la regulación infralegal resulta decisiva, en tanto se contienen normas de carácter general y abstracto que pueden aplicarse para la decisión de la cuestión de fondo, y de la cual depende aquella. Nótese, por ejemplo, el caso del Decreto № 969 de 1933 del Ministerio del Trabajo, el cual contiene el Reglamento que regula, entre otras cosas, el registro y cálculo de las horas extraordinarias, y que todavía se halla en vigor de conformidad al artículo $3^{\circ}$ transitorio del Código del Trabajo, resultando frecuentemente aplicado en sede administrativa y judicial; o el Reglamento del Registro Conservatorio de Bienes Raíces de 1857, el que contempla y regula todo el sistema registral a cargo de los Conservadores de Bienes Raíces, normas también frecuentemente decisivas (y de fondo) en cualquier asunto en que se discuta una cuestión civil registral en sede jurisdiccional. $\mathrm{O}$ la reglamentación infralegal que regula sectores completos de la actividad jurídico-material en nuestro país, como es, por ejemplo,

\footnotetext{
${ }^{30}$ NaPPI (2006), pp. 80-85.

31 Así lo ha defendido Nieva (2010), pp. 141-142, para la casación española en materia social, cuando a propósito del art. 222 de la LPL, que contempla como motivo de esta casación la «infracción legal», señala una reflexión que resulta pertinente para la casación civil chilena que considera una fórmula del motivo muy semejante. El autor español apunta que «[s]ea como fuere, sobre el motivo único de casación, la 'infracción legal', muy brevemente, debe indicarse que ha de ser posible alegar cualquier norma jurídica laboral como infringida, es decir, no solamente las que estrictamente sean 'leyes'». Y añade seguidamente que «[e]s obvio que el término 'infracción legal' está utilizado de manera impropia, por lo que debe aceptarse cualquier vulneración del ordenamiento jurídico empleada por el juez a quo en su sentencia, lo que incluye a los reglamentos, pues no hay nada que resulte más absurdo que considerar solamente las infracciones de una ley y olvidarse de las infracciones de dichos reglamentos, que no son más que explicaciones y concreciones de la ley imprescindibles para su aplicación».
} 
toda la normativa de Derecho urbanístico-inmobiliario o medioambiental, y en donde la Corte Suprema ${ }^{32}$ ha negado la cobertura casacional a las denuncias de infracción de normas reglamentarias que desarrollan o completan las normas legales que utilizan la técnica de la remisión normativa, o que regulan de forma íntegra un ámbito de la actividad jurídica.

Lo que sí sería discutible y matizable es aquello relativo a si son relevantes autónomamente las infracciones reglamentarias, pudiendo ser invocadas de forma independiente, o si estas no puedan ingresar a control casacional si no es en conjunto con las normas legales que especifican o integran, de modo que deba denunciarse la infracción de estas a raíz de la violación o incorrecta interpretación o aplicación de las normas infralegales reglamentarias. Esta última resulta ser la opción de la casación civil española ${ }^{33}$ : las normas administrativas no tienen acceso directo a la casación, de modo que siempre se deba invocar la ley integrada o desarrollada junto a la norma reglamentaria. Se señala incluso que la estimación de la denuncia solo podrá tener lugar en la medida que la norma infralegal resulta integrando y desarrollando la ley de forma armónica y consistente, puesto que, en otro caso, el Tribunal Supremo queda impedido de declarar la infracción de la norma reglamentaria que está en oposición o en contradicción a la ley que integra o desarrolla, en atención a que en la LOPJ existe el art. 6 que prohíbe a los jueces aplicar normas reglamentarias contrarias a la ley.

El razonamiento y matiz indicados parece perfectamente aplicable para el caso chileno, ya que si la norma infralegal desarrolla o integra una norma legal, la infracción de ella redunda al mismo tiempo en la infracción de un precepto legal, cuestión que ha de denunciarse conjuntamente, puesto que además de aquello el tribunal de casación debería constatar que la regulación reglamentaria infringida sea perfectamente armónica con el precepto legal que efectivamente aparece integrado o desarrollado, ya que, si no, el juez de mérito como el de casación no puede considerarse vinculado a la norma reglamentaria infralegal que se presenta en contradicción al precepto legal de rango jurídico superior (reflejo del principio de jerarquía normativa).

\footnotetext{
32 Respectivamente, véase SCS de 12 de septiembre de 2001, rol 2269-99, Legal Publishing CL/ JUR/353/2001; SCS de 30 de agosto de 2007, rol 3743-2006, Microjuris, MJCH_MJJ8168. También FERNÁNDEZ (2000), pp. 153-154, quien comenta SCS de 6 de diciembre de 1999, rol 2771-99 que contiene el mismo criterio comentado en el sentido que la infracción de norma reglamentaria no sería susceptible de ser denunciada por la vía del recurso de casación en el fondo.

33 Ortells (2010b), p. 556; Bellido (2014), p. 409. Para un análisis crítico de la propuesta contenida en la LECiv española realizado con anterioridad a su entrada en vigor, y específicamente sobre la amplitud del o los motivos de casación puede consultarse Morón Palomino (1998), pp. 29 y ss. Y para consultar la cuestión de la tradicional orientación de la casación española y la amplitud de su cobertura, de especial provecho Vázquez Sotelo (1979), y específicamente pp. 142 y ss.
} 
Con todo, la denuncia conjunta de la norma infralegal reglamentaria con la legal debe ser una exigencia cuando aquella integra o desarrolla a esta, pero no, obviamente, en el caso que la reglamentaria sea la única regulación existente que toma el lugar de lo que debería o podría estar regulado en la ley. Esta situación acontece a menudo cuando el legislador entrega de forma íntegra la regulación de una materia a la reglamentación de la autoridad, no previendo siquiera un marco regulatorio más o menos preciso. En este caso la infracción de la norma reglamentaria se hace relevante por sí misma y podrá así ser denunciada por sí sola, ya que la denuncia conjunta de una infracción de un precepto legal (que contenga un mandato jurídico de fondo) no es posible, en tanto la norma legal con frecuencia -si existe- se limita a una remisión global de una materia a la potestad reglamentaria de alguna autoridad administrativa o gubernativa.

\section{La "infracción de la jurisprudencia" como motivo de casación}

Del mismo modo, en el último tiempo se ha suscitado la cuestión de la "infracción de jurisprudencia" como motivo de casación. Con relación a este extremo existe una clara mayoría de autores que ha sostenido que en nuestro Derecho la "infracción" de aquella ${ }^{34}$ no puede configurar el motivo de casación en el fondo. Dicha mayoría apunta que esta cuestión es indiscutible, aun cuando el Proyecto de CPC de don José Bernardo Lira establecía como causal de casación en el fondo la infracción de "doctrina legal" (jurisprudencia), lo cual en definitiva no prosperó, habiendo sido eliminada del texto legal definitivo ${ }^{35}$.

Como se anticipara anteriormente, existe una posición minoritaria ${ }^{36}$ que junto con considerar que la eliminación de la "infracción de jurisprudencia" ha sido causa de incertidumbre jurídica y de dispersión de criterios en las diversas decisiones judiciales características de nuestro Derecho, estima al mismo tiempo que tal circunstancia de falta de cobertura de la "infracción jurisprudencial" con sus perniciosas consecuencias habría venido a ser corregida con la reforma de la Ley N 19.374 de febrero de 1995. Se ha dicho con antelación que esta posición ${ }^{37}$ afirma encontrar respaldo en una pretendida antinomia entre los arts. 767 y 772 . Este último, tras la reforma, ya no se refiere más a la determinación de la o las leyes infringidas como requisitos de interposición del recurso sino únicamente exige la expresión de los errores de Derecho, lo cual se ha querido considerar una suerte de cambio de fórmula en la concepción del motivo, introducido por el artículo 772, el que siendo aparentemente más amplio que

\footnotetext{
34 En realidad no existe infracción posible en tanto la jurisprudencia no constituye norma.

35 Esta idea está en Toro y Echeverría (1902), pp. 728-729, y también en Espinosa (s/f), p. 170.

36 Romero, Aguirrezábal y Baraona (2008), p. 247.

37 Véase arriba.
} 
el 767, que se sigue refiriendo a la infracción de ley, venía a quedar superado (tácitamente derogado se supone) por el art. 772. Por esta vía se quiso esgrimir una presunta ampliación del motivo del recurso de casación, con la entrada en este incluso de la "infracción de jurisprudencia". Con todo, esta posición basada en la presunta antinomia del art. 772 con el art. 767, no resulta correcta, como tampoco lo es la opinión que sostiene que la modificación del art. 772 influya en la configuración del motivo del 767, puesto que aquel precepto únicamente se encuentra previsto para la determinación de los requisitos de interposición, y que vino a quitar el excesivo rigor formal, y reconoció en definitiva el iura novit curia.

Sin embargo, la opinión criticada ha dado -en respaldo a la entrada de la "infracción de jurisprudencia"- un segundo argumento que se asila en la modificación del precepto contenido en el art. 782 CPC, y que también se introdujo con la Ley $N^{\circ}$ 19.374. En aquel precepto se implantó un cambio consistente en permitir en fase de admisibilidad el rechazo in limine por manifiesta falta de fundamento, lo cual-dicen los autores que defienden la postura- la CS ha utilizado en varias ocasiones como una vía para fortalecer su jurisprudencia, cuestión que se ha traducido en el rechazo in limine porque el recurso contradice - "infringe" - una jurisprudencia de la Sala respectiva de la CS. Al respecto cabe señalar que es evidente que tal potestad para rechazar in limine puede ser una vía para aprovechar la jurisprudencia uniforme de la Corte Suprema con el fin de resolver en el fondo un recurso de casación por medio de un procedimiento simplificadísimo, limitándose en la práctica a dar por buena la interpretación uniforme de la Corte Suprema sobre el extremo que pretende discutir el re$\operatorname{curso}^{38}$. Pero lo anterior está muy lejos de avalar la cobertura casacional de la "infracción jurisprudencial" -lo que resulta una cosa muy distinta-, consistente en pretender que constituya una forma de reconocer su carácter vinculante y la trascendencia casacional de su "infracción". Una cosa es dar por buena su propia interpretación legal, calificándola para el propósito únicamente de rechazar un recurso en oposición a ella, y otra bien distinta es predicar que la "infracción" a esa doctrina jurisprudencial constituya causal de casación en sí misma. El rechazo in limine es una decisión de fondo en donde la jurisprudencia uniforme de la CS es aprovechada como una forma de fundamentación o motivación per relationem, en virtud de la cual se da por buena (se ratifica) aquella doctrina y se desestima su revisión y modificación justamente por no existir argumentos o antecedentes que así lo ameriten. A nuestro juicio, este es el enfoque justo y completo sobre la jurisprudencia por la vía del art. 782 CPC.

\footnotetext{
${ }^{38}$ Nótese el paralelismo que puede establecerse con el modelo angloamericano, véase Summers (1997), p. 360.
} 
Por otra parte, lo anterior no opera - de iure condito-como a veces se quiere sugerir, en el sentido que la jurisprudencia ingresaría por esta vía como fuente del Derecho y que, incluso más, ella recibiría cobertura casacional. En un análisis jurídico positivo exacto, ni lo uno ni lo otro. Y ambas cosas quedan refutadas con el mismo alcance del art. 782. Como hemos apuntado, este permite el rechazo de fondo in limine, pero nunca, a la inversa, la estimación in limine por «infracción» de doctrina jurisprudencial, cuestión que supondría la censura de la sentencia impugnada justamente por contravenir (o desconocer), violar o aplicar (o inaplicar) erróneamente una doctrina jurisprudencial, a la que el juez ha de quedar sometido en tanto "norma positiva" que hace parte del ordenamiento jurídico, cuestión que a mayor abundamiento aparece expresamente proscrita en el Ordenamiento chileno por el inciso primero del art. 3 del CC.

En fin, también se ha argumentado que el mecanismo del art. 782 de rechazo in limine, en combinación con el art. 780 -que permite obtener el conocimiento en pleno del recurso cuando exista dispersión jurisprudencial- supondría el reconocimiento del carácter vinculante de la jurisprudencia ${ }^{39}$. Sin embargo, ello tampoco tiene respaldo jurídico, puesto que la misma Corte Suprema puede variar su jurisprudencia sin romper vínculo alguno, con tal que justifique razonadamente su evolución y la superación de su misma jurisprudencia. En nuestro sistema jurídico no hay norma alguna que le imponga a los tribunales sumisión a la jurisprudencia emanada de la CS. Nótese que el art. 780 CPC parte de ese supuesto, contemplando un mecanismo para unificar la jurisprudencia al interior del máximo tribunal (tribunal de casación), necesario justamente porque la propia CS no se vincula a sus precedentes, y en ese contexto normativo se buscan vías de armonización de valores opuestos: por una parte, la necesidad de unificar cuanto más se pueda (la producción sincrónica de decisiones) y, por otra, el interés de no sofocar con la vinculación jurídica la necesaria evolución jurisprudencial en el tiempo (visión diacrónica de la producción de jurisprudencia $)^{40}$.

\section{Supuestos en que limitadamente podría reconocerse relevancia a la «infracción de jurisprudencia» en casos de lagunas normativas}

\subsection{La «infracción de jurisprudencia» basada en principios generales del Derecho en supuestos de lagunas normativas}

Se ha discutido en nuestro medio la posibilidad de denunciar la «infracción» de los principios generales del Derecho, puesto que una parte de la doctrina

39 Romero, et al. (2008), pp. 248-249.

40 De allí que al interior de la misma Corte Suprema se haya discutido sobre este extremo. Véase, MuÑoz (2008), pp. 52-63. 
naciona ${ }^{41}$ ha planteado la cobertura casacional de aquella. Primeramente, es innegable que si el principio aparece normativizado en un precepto legal que lo recoja y sancione pueda invocarse infringido previsto en aquel precepto, en cuyo caso lo que se censura con la casación no es tanto la infracción del principio del Derecho, como la infracción de la propia ley que lo reconoce y le dota de eficacia jurídica.

Completamente distinto, en cambio, es el caso de la «infracción» del principio en sí mismo. A nuestro juicio la alegación de haberse infringido un principio del Derecho con completa autonomía de la ley no tiene cobertura casacional. En este caso en sentido estricto ni siquiera puede hablarse que exista una «infracción» de una norma jurídica positiva, puesto que el principio de Derecho no contiene un mandato jurídico general y abstracto, adecuado para su aplicación a un caso concreto como norma decisoria del objeto litigioso. Y por lo demás tampoco tiene respaldo normativo en el sistema jurídico chileno una pretendida relevancia casacional de la «infracción» de los principios de Derecho ${ }^{42}$.

\footnotetext{
41 Romero, et al. (2008), pp. 239-240.

42 Opinión que resulta además próxima a la sostenida por la jurisprudencia chilena. En oposición, ROMERO, et al. (2008), pp. 239-240. Nótese que los autores se refieren primero a los principios generales del Derecho y apuntan: "La dificultad en rigor surge cuando está fundamentada directamente en el principio general del derecho. En este caso, como se anticipaba, la Corte Suprema ha declarado que el tema no es susceptible de denunciarse por la vía de la casación en el fondo.»

«Entendemos que este punto reclama una profunda revisión. Si son cada vez más frecuentes los casos donde se acude a la aplicación de los principios generales, se hace evidente que estamos frente a una realidad normativa que no se puede eludir.»

«Un atisbo de cambio por parte de la Corte Suprema en esta materia se advierte en algunos pronunciamientos. Así, en la histórica sentencia de fecha 9 de mayo de 2001, nuestro máximo Tribunal procedió a validar como una auténtica norma decisioria de la litis la aplicación de una de las más típicas manifestaciones del principio general de la buena [fe], la denominada doctrina de los actos propios. Para el tema que aquí importa, la Corte Suprema le asignó a esta institución un valor normativo, admitiendo que la aplicación de esta regla es controlable a través de la casación, al declarar que aún el caso de haber existido los errores de derecho denunciados en la casación en el fondo, 'desde que igualmente la demanda habría de ser rechazada por aplicación de la doctrina de los actos propios (...)'».

«A ese pronunciamiento de la Corte Suprema se deben agregar otros por parte de los jueces del fondo, los que inspirados en la misma regla han procedido a rechazar una determinada acción por el solo hecho que la pretensión deducida era contraria a la doctrina de los actos propios.»

«Desde el punto de vista jurídico, el solo hecho que se desestime la demanda con la invocación a esta doctrina obliga a indagar acerca del control de esta decisión por la vía de la casación en el fondo. Es evidente que este tipo de sentencias no están aplicando una norma decisoria de la litis fundada en una ley, sino que todo lo contrario, resuelven la controversia a través de la nada pacíficos principios generales del derecho».

A nuestro juicio el ejemplo dado de aplicación de los principios de Derecho no pasa de ser el típico caso de consideraciones de obiter dicta y no un auténtico caso de ratio decidendi, y por lo tanto, no se constituye en verdadera aplicación de norma decisoria litis de estos principios. Pero además de aquello en el trabajo de los autores en este apartado y en otros sucesivos parece confundirse la aplicación de normas y principios con el problema de su control casacional.
} 
Especialmente interesante, por el contrario, puede ser el supuesto de la recepción de un principio jurídico en la doctrina jurisprudencial y su eventual incardinación en el motivo casacional ${ }^{43}{ }^{44}$, ya que eso permitiría viabilizar un control sobre la función de integración normativa desplegada por los jueces en casos de laguna normativa ${ }^{45}{ }_{4}^{46}$, como puede ser el supuesto de figuras jurídicas contractuales o negociales atípicas. En este supuesto lo denunciable es el principio de Derecho, pero tal como ha sido formulado por la jurisprudencia, al momento de tener que resolver casos sin una previsión positiva en el Ordenamiento. Debe aclararse que lo anterior no se constituye en una suerte de casación por infracción de jurisprudencia, sino únicamente en los casos excepcionales en donde claramente cumpla una función de integración -a falta de norma positiva-, supuesto en el cual la jurisprudencia genera (infiere) un mandato jurídico (a partir del principio) y que luego aplica ${ }^{47}$. En este caso, la integración judicial supondrá un esfuerzo de maximización del principio del Derecho, que es lo que permite que aquel funcione en una hipótesis concreta como criterio normativo de decisión ${ }^{48}$.

Lo precedente-cabe insistir-solo es posible dentro de los límites que hemos apuntado, de modo que no creemos sostenible que los principios generales del Derecho puedan tener aplicación contra legem ${ }^{49}$ y que además su infracción -en este supuesto- pueda denunciarse vía recurso de casación, pues aquello subvierte por completo nuestro sistema jurídico positivo ${ }^{50}$.

\footnotetext{
43 Morón (2001), pp. 164-165; Bellido (2014), pp. 412-413, o Serra (1993), p. 265.

${ }_{44}$ Lo indicado encuentra una cierta correspondencia en los Ordenamientos del Common Law. Véase BANKOWSKl, et al. (1997), p. 324.

45 Summers (1997), pp. 366-368, describe la función integradora de los tribunales frente a casos en donde no existe norma legal o procedente (laguna normativa) y debe ser resuelto entonces por primera vez (first impression), supuesto en el cual puede observarse cómo la jurisprudencia genera criterios de decisión basados en principios y valores destinados a colmar la laguna.

46 SerRA señala que los principios "pueden ser útiles en algunos casos extremos en que resulte muy difícil tipificar la relación jurídica sometida a la decisión judicial. En la práctica los principios de los actos propios y del enriquecimiento injusto son los más frecuentemente denunciados como infringidos en casación".

47 Boré (1988), pp. 377-379; Ortells (2010b), p. 557.

48 Con relación a la función de integración judicial mediante la maximización, es decir, por medio de la creación de criterios de decisión, puede consultarse Falcón y TeLLA (2005), pp. 147-188 y 190-191, con relación a la equidad.

${ }^{49}$ FalCón y Tella (2005), pp. 190-191.

${ }^{50}$ Otra cosa -obviamente distinta- es que los principios generales de la legislación deban considerarse como constitutivos de un elemento de interpretación, conforme lo reconoce el art. 24 CC., pero a través de esta vía -como es natural- no se puede acabar en la aplicación de un precepto inaplicable o en la inaplicación de un precepto aplicable, sino a lo sumo intentado una interpretación armónica con un principio jurídico, en cuanto aquello sea plausible en el caso.
} 


\subsection{La "infracción de jurisprudencia" basada en la equidad en supuestos de laguna normativa}

Se han producido asimismo referencias dogmáticas a la equidad y a la trascendencia casacional de su "infracción". La equidad en nuestro Ordenamiento tiene reconocimiento como fuente del Derecho supletoria, tal como se desprende de los artículos 170 N 5 CPC y 10 COT, a la cual el juez debe acudir cuando se halla en la necesidad de integrar el Ordenamiento en caso que este no contemple norma positiva que resuelva un asunto ${ }^{51}$.

La necesidad de control de las decisiones de esta especie parece venir provocada por el innegable grado de incerteza jurídica que representa la misma como criterio normativo para la decisión del asunto. En cuanto al control casacional de la decisión apoyada en la equidad debe observarse que desde un cierto punto de vista la situación es análoga a la de la costumbre, ya que tanto una como otra -de forma supletoria- toman el lugar de la norma positiva que se necesita para resolver (norma decisoria litis) el asunto que se ha planteado. Desde este punto de vista parece sensato un control casacional sobre la aplicación de la equidad al caso concreto, del mismo modo que se consiente respecto a la costumbre, puesto que en ambos supuestos nos encontramos con fuentes normativas que toman el lugar de la norma positiva, valiendo como si lo fuesen, por expresa disposición legal que así lo prevé. Y resulta sensato consentir el control casacional, ya que también habría necesidad de nomofilaxis, vale decir, de defensa del Derecho, tanto como de unificación jurisprudencial acerca de la interpretación de aquel.

Sin embargo, hay también una diferencia entre costumbre y equidad, y que bien puede hacer surgir la duda sobre la pertinencia de la relevancia casacional de la infracción normativa en el segundo supuesto. Aquella estriba en que la costumbre opera como fuente del Derecho de la que emana una norma (mandato normativo) con un grado de definición que hace indudable su entidad o existencia propia, objetivamente constatable (cuestión que incluso habrá de acreditarse), y fijada la misma el juzgador deberá proceder a determinar su relevancia para el caso e interpretarla -atribuyéndole un significado-y a aplicarla al caso concreto. En cambio, la equidad no resulta sino una remisión abstracta

51 Cabe hacer la precisión de que lo dicho no debe ser confundido con la función hermenéutica de la equidad natural del art. 24 CC: tampoco por esta vía (ni por otra) se puede llegar a suscribir la afirmación de que la invocación de la equidad permita desvincularse del Derecho positivo, pues ella sólo resulta en nuestro sistema una fuente supletoria o un elemento de interpretación, pero ni aun en este caso -como elemento de interpretación- permite eludir la atribución de significado correcto a la norma positiva, con independencia de las preferencias del intérprete sobre lo que resulta o no equitativo. Por eso discrepamos de las opiniones que creen posible el recurso a la equidad incluso contra legem. En esta posición ROMERO, et al. (2008), pp. 240-246. 
-casi una interpelación al sentido de recta consciencia jurídica del juzgadory en consecuencia la norma o mandato jurídico, más que ser investigado y acreditado en su entidad y contenido, viene (re)construido por el juzgador, y allí la creación, la interpretación y la aplicación de la norma aparece como un proceso mucho menos plausible de separación y distinción concreta. Con todo, aun con esta gran diferencia puede ser útil la cobertura casacional en el sentido que las decisiones en equidad, supletorias del vacío legal habrán de crear una jurisprudencia susceptible de consolidarse y de valer-mientras el vacío permanezca-como fuente orientadora de nuevas decisiones de equidad, con lo cual se presenta como algo deseable alcanzar una cierta estabilidad y certeza en las futuras decisiones basadas en ella, lo que convendría asegurar mediante la casación.

El control casacional de la equidad puede ser correctamente articulado solo si se cuenta con el establecimiento de criterios normativos estables, desarroIlados por la doctrina jurisprudencial. El mismo criterio de decisión o máxima judicial basado en la equidad ${ }^{52}$ debe estar fijado y dotado de contenido por la jurisprudencia, puesto que es esto lo que permite adoptar una decisión y posteriormente hace posible el control casacional y la correspondiente evaluación de la «infracción» denunciada ${ }^{53}$ con respecto al criterio de equidad previamente fijado.

\section{Posible incidencia de la reforma procesal civil en la configuración de un motivo de naturaleza casacional}

Todo lo dicho anteriormente pone -a nuestro juicio- en evidencia la conveniencia de aprovechar la reforma al proceso civil que se discute en el Congreso para la precisa regulación del motivo o motivos del recurso de naturaleza casacional que se quiera establecer, circunstancia que permitiría actualizar la concepción de este extremo fundamental en la configuración de un recurso extraordinario, con independencia de su precisa denominación. Sin embargo el proyecto de CPC no ha asumido esta cuestión en su propuesta. Incluso al contrario, en determinados aspectos introduce notas de confusión que pueden constituirse en fuentes de incertidumbre jurídica en el futuro.

\footnotetext{
52 FalCón y Tella (2005), pp. 147-188 y 190-191.

${ }^{53}$ Con respecto a cómo debiera articularse el control casacional atendida la naturaleza de la decisión en equidad, autores como Romero, et al. (2008), p. 246, apelan a la técnica del control "que se realiza en relación al ejercicio de facultades discrecionales de la autoridad administrativa", lo cual supone atribuir también este carácter a la decisión jurisdiccional basada en la equidad, cuestión que no nos parece completamente certera.
} 
Así, el Proyecto no trata claramente el establecimiento de los motivos del recurso, sino de una manera implícita y ambigua. El análisis debe centrarse en los arts. 405 y 409 del Proyecto ${ }^{54}$.

El encabezamiento del primero (art. 405) dice referirse al objeto del recurso extraordinario, lo cual podría suponer una alusión a la pretensión recursiva o a los posibles motivos que puedan fundar la pretensión. No obstante, el precepto del art. 405 dispone lo que sigue: «Objeto. El agraviado por una sentencia podrá ocurrir excepcionalmente ante la Corte Suprema con los propósitos que en este título se señalan y cumpliéndose los requisitos que se indican, para solicitarle que se avoque al conocimiento del asunto por estimarse afectado un interés general», y lo cierto es que el precepto no se refiere en absoluto ni a lo uno ni a lo otro, y al final contiene una referencia oblicua a la competencia funcional de la Corte Suprema, además de un manifiesto error sintáctico y jurídico, como es aquella mención vacía que refiere que la Corte Suprema deba «avocarse al conocimiento del asunto". ¿De qué asunto? No se sabe, puesto que no se ha dicho nada sobre los motivos del recurso ni tampoco sobre la pretensión recursiva. Una buena técnica legislativa -en nuestra opinión-sería partir sistemáticamente señalando primero los motivos y luego la pretensión recursiva. Y solo habiendo apuntado y distinguido bien estas dos cosas cabe hacer referencia a la cuestión del interés general (casacional), si con ello se quiere introducir alguna forma de selección de asuntos. A este respecto no está de más tener presente que el motivo fija la sustancia de lo que es denunciable por la vía del recurso de casación o extraordinario, mientras que el interés general (o casacional) opera como un requisito concreto aplicable al momento del juicio de admisibilidad (selección concreta de asuntos).

Así, resulta imprescindible regular nítidamente los motivos del recurso, y consagrar claramente que un motivo del recurso consiste en el error en la determinación, interpretación o aplicación de una norma de derecho positivo material, o de doctrina jurisprudencial, cuando ésta complementa o completa un precepto jurídico, o reconoce y aplica la costumbre o un principio jurídico ${ }^{55}$.

La referencia al Derecho positivo material puede resultar una obviedad, pero lo cierto es que tal como está concebido el denominado recurso extraordinario (en su lagunosa regulación), aquello no aparece cubierto, por sorprendente que parezca esta afirmación.

\footnotetext{
${ }^{54}$ Al respecto Del Río (2012), pp. 280-283. También confróntese Delgado (2012), pp. 131 y ss.

55 Nótese que las Actas de la Comisión Revisora del Proyecto de Código de Procedimiento Civil, en su sesión 85, llegó a establecer que la doctrina legal del precepto del proyecto (artículo 791) debía entenderse como "la que, derivaba más o menos directamente de la ley o de los principios y reglas del derecho, se halla generalmente recibida por la jurisprudencia de los tribunales". Véase, EspinosA (s/f), p. 170.
} 
Con respecto al problema esencial de la confusa regulación también hay que atender al artículo 409. Este dispone lo siguiente:

«Interés general. La Corte Suprema determinará avocarse al conocimiento del asunto cuando la mayoría de los miembros de la sala respectiva estime que concurre un interés general que haga necesaria su intervención».

«Solo podrá estimarse que concurre un interés para avocarse al conocimiento del asunto en los siguientes casos:»

«a) Cuando se hubiere infringido en forma esencial, en la sentencia o en el procedimiento del cual ella emanare, un derecho o garantía fundamental contemplado en la Constitución Política de la República o en los tratados internacionales ratificados por Chile y que se encuentren vigentes $\mathrm{y} ;$;

«b) En caso que considere pertinente fijar, uniformar, aclarar o modificar, una doctrina jurisprudencial».

El precepto citado, como se ve, lleva por encabezado exactamente el denominado «interés general», y pretende la regulación de esto omitiendo, sin embargo, el tratamiento previo del motivo o motivos de casación. Y con ese equívoco se corre el riesgo de entender que el motivo no importa o no existe o que el interés general toma su lugar, y ello acabe derivando en la conclusión de que tal cosa al final resulta en una suerte de autorización abierta o ilimitada para la selección discrecional de asuntos.

Dicho de otra manera: el artículo 409 dice establecer criterios sobre lo que habrá de entenderse por interés general, aun cuando confusamente y con prescindencia de los motivos del recurso. No ha advertido el prelegislador que en un recurso extraordinario o de naturaleza casacional si hay algo que debe estar claro es justamente sobre qué tipos de infracciones de Derecho se autoriza la impugnación ${ }^{56}$. Es más, un modelamiento de un pretendido interés general requiere de aquello también. En otro caso, ¿sobre qué cosas entonces se modela ese interés?

Por lo demás, como advertíamos antes, si consideramos al artículo 409, por el contrario, desde la perspectiva de los motivos, se observa que su cobertura es completamente deficitaria e insatisfactoria, pues en el primer supuesto hace referencia a la infracción esencial de derechos o garantías fundamentales, casi en idénticos términos al art. 373 letra a) del CPP, aunque obviamente en el proceso civil tenga menos trascendencia práctica que en el proceso penal y, por supuesto, mucho menos relevancia que la infracción de

56 Una observación semejante hace DeLGADO (2012), p. 131. 
otras fuentes normativas, partiendo por la legal, las que aparecen inexplicablemente preteridas ${ }^{57}$.

En cuanto al segundo criterio de interés general (si acaso en lugar del motivo), el cual está referido a la necesidad de crear, fijar o modificar jurisprudencia, Ilama la atención que la misma se predique respecto de una categoría jurídica indeterminada, que no se sabe si goza o no de autonomía respecto de las normas de Derecho positivo.

Por otra parte, con respecto a ese mismo supuesto del artículo 409 del Proyecto, parece del todo conveniente dar un preciso concepto legal vinculante de cuándo se va a entender formada la mencionada doctrina jurisprudencial (consistente y uniforme), lo que requiere de la específica fijación de criterios cuantitativos, como la cantidad de fallos que la configuran -dos o más-; de los criterios cualitativos, tal como la determinación de qué órganos deba derivar esa doctrina jurisprudencial -si solo doctrina de la Corte Suprema o también de Cortes de Apelaciones-; de los criterios temporales, esto es, en qué época deba haberse producido la jurisprudencia que configura la doctrina jurisprudencial -si períodos breves, o más bien amplios, con tal que no aparezca contradicha-.

Lo que parece desaconsejable es señalar lo de la doctrina jurisprudencial y no hacer mención alguna a las cuestiones precedentes, menos si se tiene en cuenta nuestro débil desarrollo jurídico, tanto práctico como doctrinal, cuestión que hace sumamente riesgoso y poco sensato dejar conferidas estas cuestiones a un presunto desarrollo supletorio a cargo de la jurisprudencia o de la dogmática ${ }^{58}$.

En fin, la correcta distinción entre motivo (la infracción de norma de Derecho) y el interés casacional en lugar del tratamiento único del interés general con referencia a la doctrina jurisprudencial sin más, omitiendo el tratamiento del motivo del recurso, resulta decisiva. En efecto, en el primer caso aquella referencia a la doctrina jurisprudencial estaría conectada esencialmente a la interpretación judicial respecto de una norma. En el segundo supuesto, en cambio, podría sugerirse la errada idea de estar refiriéndose al concepto de precedente o jurisprudencia como fuente formal y autónoma en sí mismo. Y en este segundo caso lo más absurdo es que se constituiría

\footnotetext{
57 Del Río (2012), p. 282.

${ }^{58}$ Cabe observar que de algún modo un problema ocasionado por razones semejantes se ha presentado con la aplicación de la norma prevista en el art. 780 del CPC, en relación con el art. 782, que contemplan la posibilidad de pedir que un recurso de casación en el fondo sea conocido y resuelto por el pleno de la Corte Suprema, en el caso que existan diversas interpretaciones jurídicas sostenidas en distintos fallos por la misma Corte Suprema. La falta de regulación y precisión ha influido en la práctica inaplicación del precepto en cuestión. Véase en términos generales, MosQuera y Maturana (2010), pp. 312-313.
} 
en motivo (o en interés) la infracción de un precedente, pero no la violación o infracción de una norma de Derecho positivo. De hecho -como ya se ha dicho- esta hipótesis no aparece precisamente cubierta. De esta manera el recurso extraordinario aparece completa y totalmente desvinculado a la finalidad nomofiláctica o de defensa del Derecho positivo, salvo en los limitados márgenes en que se pueda entender lesionado un derecho fundamental, en tanto cabe concluir que aquello supone al tiempo la infracción de la correspondiente norma constitucional que lo reconoce ${ }^{59}$.

\section{La incidencia de la reforma con relación a la infracción de normas reguladoras de la prueba}

Cabe sopesar, por último, la propuesta de reforma del proceso civil con relación a las repercusiones que pueda tener sobre el motivo del recurso de casación y la cobertura de la infracción de las denominadas leyes reguladoras de la prueba, extremo que se presenta necesitado de análisis no solamente por el acusado déficit técnico en el Proyecto respecto de la regulación del denominado recurso extraordinario, tal como hemos intentado explicar en el apartado anterior, sino además porque en el mismo se proponen modificaciones sobre el régimen probatorio que pueden - prima facie- hacer dudar sobre la mantención y la pertinencia de la denominada infracción de las leyes reguladoras de la prueba como infracción casacionalmente relevante, tal cual tradicionalmente se ha considerado en la casación chilena.

La jurisprudencia de la Corte Suprema ha tenido en el tiempo ciertas posiciones bastante estables, al menos en vía de principios, como es, por ejemplo, que el recurso de casación en el fondo sea medio adecuado para censurar las infracciones de ley «llamadas a dirimir la controversia» o denominadas "decisoria Litis"60. En segundo lugar, y derivado de lo anterior, ha sostenido de forma invariable que quedan excluidos del examen casacional (de fondo) los errores in procedendo o de inejecución de normas procesales y los errores en el juicio de hecho. Y justamente con relación a este último extremo, estima que las infracciones de las normas reguladoras de la prueba se presentan como una matización a lo indicado precedentemente, puesto que la denuncia de una de esas infracciones sí podría derivar no obstante en la censura casacional al juicio de hecho que resulta de aquella.

59 Del Río (2012), p. 282.

${ }^{60}$ Otras veces utiliza como expresión equivalente -aunque técnicamente no lo sea- aquella que señala que la infracción de ley relevante para la casación en el fondo es la que está referida a la ley sustantiva o material. 
Con respecto a este tema, la jurisprudencia de la Corte Suprema ${ }^{61}$ ha dado un concepto prácticamente invariable sobre las leyes reguladoras, considerando que son las que establecen y determinan la carga de la prueba, las que determinan los medios (fuentes) de prueba admisibles, las que determinan el valor probatorio de un medio de prueba en particular y las que fijan las preferencias de unos sobre otros, de forma vinculante para el juzgador. Aparejado a lo anterior la misma jurisprudencia suele ofrecer ideas que permiten modelar la naturaleza de la categoría jurídica de dichas normas reguladoras, indicando al respecto que estas constituyen normas básicas de juzgamiento fáctico, que contienen deberes, limitaciones o prohibiciones a que deben sujetarse los jueces ${ }^{62}$.

Generalmente la jurisprudencia de la Corte Suprema ofrece en sus decisiones una consagración de los supuestos normativos en que va a considerar que aquellas son infringidas. Encontramos al respecto una declaración clásica sobre este asunto, la que señala que "se entienden vulneradas las normas reguladoras de la prueba, fundamentalmente, cuando los sentenciadores invierten el onus probandi; rechazan las pruebas que la ley admite, aceptan las que la ley rechaza, desconocen el valor probatorio de las que se produjeron en el proceso cuando la ley les asigna uno determinado de carácter obligatorio o alteran el orden de precedencia que la ley les diere". Esta declaración se repite prácticamente en los mismos términos en casi todas las sentencias de la Corte Suprema que analizan la materia ${ }^{63}$.

Así, de la jurisprudencia de la Corte Suprema se desprende claramente el concepto de leyes reguladoras de la prueba y los tipos de normas que quedan comprendidas dentro de este, tanto como las hipótesis de infracción que se

${ }^{61}$ SCS de 4 de enero de 2001, RDJ, t. 98, sec. $1^{\text {a }}$; SCS, rol 6783-2008, de 7 de diciembre de 2009, Legal Publishing CL/JUR/4502/2009; SCS, rol 1343-2008, de 15 de diciembre de 2009, Legal Publishing CL/ JUR/4841/2009; SCS, rol 4118-2010, de 7 de octubre de 2010, Legal Publishing CL/JUR/8069/2010; SCS, rol 2281-2010, de 13 de octubre de 2010, Legal Publishing CL/JUR/8194/2010; SCS, rol 49942008, de 26 de octubre de 2010, Legal Publishing CL/JUR/8802/2010; SCS, rol 7535-2009, de 4 de mayo de 2011, Legal Publishing CL/JUR/9689/2011; SCS, rol 5037-2011, de 6 de julio de 2011, Legal Publishing CL/JUR/5429/2011; SCS, rol 6661-2009, de 12 de agosto de 2011, Legal Publishing CL/ JUR/6510/2011; SCS, rol 7803-12, de 30 de noviembre de 2012, Legal Publishing CL/JUR/2762/2012; SCS, rol 11908-2011, de 20 de marzo de 2013, Legal Publishing CL/JUR/618/2013.

${ }^{62}$ Véase. por todas SCS, rol 7803-12, de 30 de noviembre de 2012, Legal Publishing CL/JUR/2762/2012.

${ }^{63}$ SCS de 4 de enero de 2001, RDJ, t. 98, sec. 1a; SCS, rol 6783-2008, de 7 de diciembre de 2009, Legal Publishing CL/JUR/4502/2009; SCS, rol 1343-2008, de 15 de diciembre de 2009, Legal Publishing CL/ JUR/4841/2009; SCS, rol 4118-2010, de 7 de octubre de 2010, Legal Publishing CL/JUR/8069/2010; SCS, rol 2281-2010, de 13 de octubre de 2010, Legal Publishing CL/JUR/8194/2010; SCS, rol 49942008, de 26 de octubre de 2010, Legal Publishing CL/JUR/8802/2010; SCS, rol 7535-2009, de 4 de mayo de 2011, Legal Publishing CL/JUR/9689/2011; SCS, rol 5037-2011, de 6 de julio de 2011, Legal Publishing CL/JUR/5429/2011; SCS, rol 6661-2009, de 12 de agosto de 2011, Legal Publishing CL/ JUR/6510/2011; SCS, rol 7803-12, de 30 de noviembre de 2012, Legal Publishing CL/JUR/2762/2012; SCS, rol 11908-2011, de 20 de marzo de 2013, Legal Publishing CL/JUR/618/2013. 
puedan verificar a su respecto. Ahora bien, la reforma al proceso civil proyectada -como anticipábamos- plantea la cuestión de determinar cuán alterado podría verse lo descrito por influjo de aquella. Las principales dudas podrían venir provocadas por la cuestión de si lo precedente no tendría que tender a la desaparición en un sistema de libertad probatoria y en donde impere la valoración conforme la sana crítica y, por otra, si un efecto también semejante no debiera producirse así mismo con el establecimiento de la determinación judicial-que no legal-de la carga de la prueba en lo que se ha denominado por algunos como carga dinámica de la prueba. Seguidamente analizamos cada situación separadamente.

\subsection{Libertad probatoria e infracción de las leyes reguladoras que determinan los medios de prueba admisibles (rectius, eficaces) o establecen limitaciones probatorias específicas}

Con relación a este primer punto se puede estimar que en un modelo procesal con libertad probatoria (de medios) para la acreditación de los hechos necesitados de prueba se excluya naturalmente el planteamiento de la infracción de leyes reguladoras sobre este extremo, en tanto no parece pertinente plantearse un quebrantamiento de un mandato jurídico vinculante para el juez al momento de juzgar y dar por probado un hecho con base en la acreditación de aquel por un medio de prueba legalmente privado de eficacia probatoria con relación a un hecho determinado.

Precisamente el Proyecto de CPC en su art. 286 inciso $1^{\circ}$ dispone que "(...) Todos los hechos y circunstancias pertinentes para la adecuada solución del conflicto sometido a la decisión del tribunal podrán ser probadas por cualquier medio obtenido, ofrecido e incorporado al proceso en conformidad a la ley". Un precepto como el transcrito aparece estableciendo un régimen de libertad probatoria que sustituye el régimen legal de prueba que con matices está vigente en nuestro proceso civil y que se caracteriza por el establecimiento o determinación de las fuentes de prueba que se puedan aportar al proceso, excluyendo a todas las demás no expresamente previstas en la norma.

Con todo, para ser más exactos, cabe consignar que nuestro proceso civil en vigor solo consulta un sistema de prueba legal atenuado. En efecto, ello es así, aun cuando existan preceptos como los de los arts. 341 CPC y 1698 inciso $2^{\circ}$ del CC. Si bien estos preceptos no distinguen entre fuente y medio de prueba (como se hace en la dogmática moderna), lo que habría permitido encauzar cualquier soporte en donde conste información sobre un hecho por la vía de un medio de prueba legal (el procedimiento legal a través del cual ingresa al proceso la información contenida en la fuente), lo cierto es que lo anterior no es un óbice insalvable para concluir en una interpretación semejante a la indicada, 
basándose exactamente en la distinción técnica antes señalada, cuestión que en definitiva le acabaría restando el carácter restrictivo al denominado sistema de prueba legal en vigor. Pero además de lo anterior y asumiendo que los arts. 341 CPC y 1698 inciso $2^{\circ}$ del CPC pretendiesen limitar las fuentes probatorias, y no determinar solamente los medios o procedimientos probatorios previstos en el proceso civil, los mismos tampoco causarían gran constricción en orden a limitar las posibilidades de aportación de fuentes de prueba con eficacia probatoria, en tanto las hipótesis posibles de fuentes acaban encontrando siempre acomodo en algunos de aquellos «medios de prueba» legalmente previstos. Y los casos que en algún momento pudieron plantear alguna duda interpretativa han quedado despejados por expresa disposición legal a favor de la permisión de una fuente probatoria respecto de la cual hubiesen existido eventuales reparos o dificultades para incardinarla en algún «medio» legal, tal como acontece con el art. 348 bis CPC.

Ahora bien, y no obstante lo apuntado, en la ley perduran limitaciones probatorias específicas, como acontece con las inhabilidades de los testigos en virtud de las cuales no se consiente el aprovechamiento de la declaración testifical de determinados sujetos, o el supuesto del art. 402 del CPC referido a la confesión de hechos personales ${ }^{64}$, o también los diversos supuestos de presunciones de Derecho que impiden prueba en contrario, o así mismo la más relevante como resulta ser la limitación probatoria para la acreditación de determinados actos jurídicos que no pueden probarse sino únicamente por la fuente documental y a través de la prueba documental ${ }^{65}$. Estas normas son sin duda leyes reguladoras de la prueba. En todos estos casos es perfectamente plausible plantearse una infracción a estas leyes reguladoras de la prueba con relevancia casacional. ¿Desaparecen todas estas situaciones con el Proyecto, de modo que hace inconducente formularse la cuestión de la necesaria cobertura recursiva de las infracciones de las leyes reguladoras indicadas? Estimamos que la respuesta a la cuestión debe ser negativa. Ciertamente desaparecen los casos específicos de la confesión (del 402 CPC) y los de la inhabilidad de testigos (de los arts. 357 y 358 CPC), en tanto la regulación proyectada establece una normativa que prescinde de aquellos. Sin embargo subsisten, por ejemplo, las presunciones de Derecho que impiden toda prueba en contrario del hecho presumido como una limitación absoluta determinada -sobre un hecho determinado que se presume--, puesto que el Código proyectado expresamente lo establece así en el art. 295 inc. 30. También van a subsistir sin duda aquellas normas reguladoras de la prueba que limitan la acreditación de determinados

64 SCS, rol 7535-2009, de 4 de mayo de 2011, Legal Publishing CL/JUR/9689/2011, que estima la infracción de la norma reguladora sobre la prueba confesional.

${ }^{65}$ SCS, rol 11908-2011, de 20 de marzo de 2013, Legal Publishing CL/JUR/618/2013, que estima la infracción de la norma reguladora de la prueba del art. 1700 CC. 
actos jurídicos, que únicamente podrían probarse con los documentos que dan cuenta de los mismos, y prohíben la prueba por otra fuente y medio, ya que la propuesta de nuevo Código contempla este supuesto expresamente en su artículo $295^{66}$. El precepto en cuestión señala que "[s] in embargo el acto o contrato solemne sólo puede ser acreditado por medio de la solemnidad prevista por el legislador", con lo cual la limitación probatoria que se consagra resultaría ser semejante a la prevista en el artículo 1701 del Código Civil. Pero, por el contrario, no quedarían comprendidas las limitaciones probatorias previstas en los arts. 1709 y 1710 del CC relativas a los actos o contratos que contengan la entrega o promesa de una cosa que valga más de 2 UTM o la demanda de un crédito que debía ser consignado por escrito y no lo fue. Existiendo norma expresa que limita la prohibición probatoria para los actos solemnes, los cuales no podrían ser probados sino por la correspondiente solemnidad, las otras limitaciones legales quedarían tácitamente derogadas por la norma que consagra la regla general de la libertad probatoria.

\subsection{La valoración de la prueba conforme la sana crítica y su incidencia en la infracción de las leyes reguladoras que tasan el valor de los medios de prueba}

Respecto a la infracción de las leyes reguladoras que fijan el valor probatorio de los medios, debe apuntarse que efectivamente en el proceso civil existen variadas normas legales de tasación probatoria de diversos medios de prueba que constriñen los márgenes de ponderación racional del juez, el cual queda en una medida más o menos relevante sometido a la estimación y a la ponderación-singular y comparativa- legalmente orientadas por normas precisas, las que naturalmente se constituyen en leyes reguladoras de la prueba, tal como las ha entendido la Corte Suprema. Existen en nuestro Derecho vigente múltiples ejemplos consagrados en el CPC y en otros cuerpos legales, como son los casos del valor de la confesión, según arts. 399 y 402 del CPC y 1713 del CC ${ }^{67}$; o aquel del precepto contenido en el art. 398 del CPC, sobre la confesión extrajudicial; o el del art. 408 del CPC, sobre el valor de la inspección personal; o el del art. 1700 del $\mathrm{CC}^{68}$ con relación al valor del instrumento público, y el del art. 1702 del CC con relación al art. 346 del CPC, respecto de los instrumentos

\footnotetext{
66 El artículo 295 del PCPC está previsto dentro de las normas referidas a la valoración de la prueba, en lugar de ubicarla -en donde debía- en el artículo 286 como una matización o excepción a la regla general de la libertad de medios probatorios.

67 SCS, rol 7535-2009, de 4 de mayo de 2011, Legal Publishing CL/JUR/9689/2011, que estima la infracción de la norma reguladora sobre la prueba confesional.

${ }^{68}$ SCS, rol 11908-2011, de 20 de marzo de 2013, Legal Publishing CL/JUR/618/2013, que estima la infracción de la norma reguladora de la prueba del art. 1700 CC.
} 
privados reconocidos o mandados a tener por reconocidos, o el caso de la presunción legal de los hechos declarados probados en otro juicio entre las mismas partes, conforme lo dispone el art. 427 inc. $2^{\circ}$ del CPC, y el caso del mismo art. 427 inciso $1^{\circ}$, respecto de un hecho certificado por un ministro de fe, el que se entenderá acreditado salvo que hubiere prueba en contrario que le permita al juez desvincularse del mandato acerca del valor prefijado ex lege. En estos supuestos -como en varios otros- se está en presencia de leyes reguladoras de la prueba que son entonces susceptibles de ser infringidas si no son observadas por el juzgador en su juicio de hecho, y son en consecuencia también denunciables vía recurso de casación.

¿Desaparecen estas leyes reguladoras con la propuesta legislativa de modo que a su respecto no quepa ya plantearse la necesidad de cobertura recursiva? La respuesta exacta de nuevo es negativa ${ }^{69}$. El precepto contemplado en el Proyecto en el art. 295 inciso $1^{\circ}$ dispone que la valoración de la prueba se hará conforme la sana crítica «[s]alvo que la ley atribuya un valor determinado a un medio probatorio», cuestión que luego aparece refrendada en el art. 297 inciso $1^{\circ}$. Así, por ejemplo, el art. 306 inciso $1^{\circ}$ del Proyecto confiere valor de plena prueba a los instrumentos públicos (repitiendo en lo sustancial lo señalado en el art. 1700 del CC). En consecuencia, deberá estarse a los principios de la lógica, a las máximas de la experiencia y a los conocimientos científicamente afianzados en la ponderación de la prueba, salvo texto legal que expresamente contemple una regla de apreciación diversa. Podemos inferir que la intención del Proyecto es la de armonizar la regla general de valoración racional de la sana crítica con la existencia de normas especiales que contemplen reglas legales de ponderación para determinados medios o supuestos. Con lo expuesto cabe concluir que si bien el Proyecto parece invertir la regla imperante en nuestro CPC vigente, estableciendo por regla general la valoración libre de pautas o tasaciones legales, lo cierto es que subsiste la norma de tasación más relevante en el ámbito del proceso civil como es aquella expresamente consagrada en el art. 306 del Proyecto y así mismo también subsisten todas aquellas normas previstas en leyes especiales, puesto que así lo consienten los arts. 295 inciso $1^{\circ}$ y 297 inciso $1^{\circ}$ del Proyecto.

${ }^{69}$ En este punto además debe advertirse que aun en un sistema de libre valoración (valoración racional) es posible defender la necesidad de ofrecer tutela casacional ante una valoración manifiestamente irracional o absurda. Véase VÁzquez Sotelo (1979), p. 142; Morón Palomino (1998), p. 9, y de él mismo (2001), pp. 175 y ss. Actualmente estos asuntos específicamente mencionados parecen encontrar mejor cauce como motivo del denominado recurso extraordinario, conforme fluye del artículo 469.1.2 ${ }^{\circ}$ de la LECiv, conforme lo indica, entre otros BeLLIDo (2013), pp. 231 y ss. Nótese sin embargo que igual predicamento no es trasladable para el caso de las normas de valoración legal, que en cuanto infracción in iudicando debe continuar siendo incardinada en el motivo de casación, aunque ese no haya sido el parecer jurisprudencial. Véase por todos a OrTells (2014), pp. 446-448. 


\subsection{La carga de la prueba como ley reguladora de la prueba y la relevancia casacional de su infracción}

Conforme a la legislación vigente, por último, no cabe duda que la carga de la prueba viene siempre legalmente establecida y que el juzgador se halla irremisiblemente sometido en su enjuiciamiento de hecho a las normas legales que la configuran. Por esta razón es que la Corte Suprema la considera uno de los tipos de norma reguladora de la prueba ${ }^{70}$. De allí que tampoco quepa duda sobre la cobertura casacional de la infracción de las normas que establecen la carga de la prueba aplicable al caso.

Con todo, tocante a este aspecto corresponde apuntar que la norma sobre carga de la prueba prevista inicialmente en el Proyecto junto con dar una regla legal de distribución de aquella entre las partes (semejante a la del art. 1698 del CC), le permitiría al juez modificarla en función de la facilidad o disponibilidad probatoria de las mismas ${ }^{71}$, cuestión que -según la norma- quedaba únicamente sometida al requisito de comunicar la alteración judicial de la distribución legal, con el propósito de ofrecerle un tiempo y oportunidad adecuados a las partes para reaccionar ante ella y evitar las consecuencias negativas que se podían derivar si no evacuaban suficientemente la mencionada carga (ahora judicial, y no legal $)^{72}$. Esta regla consentía la alteración judicial de la regla legal, y fue denominada por algunos como la carga dinámica de la prueba ${ }^{73-74}$.

${ }^{70}$ Con todo, nótese cómo Michelı (1961) en varios lugares de la obra y especialmente p. 235, insiste en la idea que la carga de la prueba es esencialmente una regla de juicio, y en cuanto tal distinta de las denominadas reglas de prueba, no obstante lo cual entiende que se traduce igualmente en un error in iudicando al cual debe darse cobertura casacional. Estima desde la perspectiva del motivo de casación que la infracción de las reglas de la carga de la prueba constituye un error in iudicando de iure procedendi que se traduce en una infracción sustancial de derecho. Así el autor quiere remarcar de la utilización de la regla de juicio en el confín del derecho procesal, donde se contempla la disciplina de la actividad de enjuiciamiento destinada a declarar una precisa aplicación de norma sustancial en razón del o de los criterios de distribución de la prueba de los supuestos fáctico normativos de aquella. Por eso las reglas sobre la carga de la prueba se han considerado que constituyen lo que se denomina "el derecho para la aplicación del derecho".

71 Al respecto, pueden consultarse las reflexiones de LarRocau (2014), pp. 65-72.

72 Corral (2012), pp. 107-117, y también Domínguez (2013), pp. 787-798.

73 Una explicación crítica sobre la propuesta legislativa inicial puede encontrarse en CORRAL (2012), pp. 107-117, y en la misma línea Domínguez (2013), pp. 787-798. Confróntese González (2013), pp. 13 y ss.

${ }^{74}$ Con independencia de la discutible denominación de la regla contenida en el art. 294 inciso $2^{\circ}$ del Proyecto, como "carga dinámica de la prueba", el punto relevante es determinar a qué cosa exactamente se está autorizando al juez con ese precepto. ¿Se le está autorizando al juez a hacer aquello que a menudo hace el legislador, como es presumir determinados hechos y por esa vía a desplazar el objeto de prueba al hecho que excluye o le priva de eficacia a aquel? Con todo, aun en ese caso la parte favorecida con la modificación habrá de probar como mínimo el supuesto del que arranca la inferencia judicial. ¿O se estará autorizando al juez a poner la carga subjetiva en un sujeto distinto 
Desde luego un cambio como el que se describe incidiría en nuestro objeto de análisis puesto que el juez de mérito no incurriría en infracción de norma legal sobre la carga probatoria si ha procedido a una redistribución previa diversa a la legalmente correspondiente. Y a la inversa, la infracción de la regla de carga probatoria concurriría únicamente cuando el juzgador en su fallo desatienda la regla sin más, sin antes haber procedido a su alteración y a la comunicación debida de esa alteración. Pero mediando la debida y oportuna comunicación, la norma legal le consentiría alterar la carga legal de la prueba, atendiendo a los criterios de disponibilidad y facilidad que concretamente pueda presentarse en un caso con relación a las partes, y juzgar conforme a la propia alteración de la carga. Podría surgir únicamente la duda de si el juez -habiendo alterado ex ante la carga y comunicada esta a las partes en forma oportuna- pueda desatender su propia redistribución y volver (atenerse) a la regla legal en su juicio. Aquello podría tener trascendencia casacional en tanto pudiese esgrimirse que tal situación implica una infracción normativa al pasar por encima de su propia redistribución de carga y aplicar la regla legal, puesto que en ese caso no solo acabaría desoyendo su propia redistribución, sino además infringiendo el mismo precepto (294 inciso segundo) que contempla esta redistribución y que da a entender que el juicio de fondo habrá de ajustarse a aquella no pudiendo luego el juzgador acabar volviendo a la carga legal. Sin embargo, este extremo de la propuesta contenida en el Proyecto ha sido eliminado a raíz del debate y tramitación legislativos -en el primer trámite constitucional en la Cámara de Diputados- como consta en Acta de Sesión 117 a de 22 de enero de 2014, Legislatura $361^{\text {a }}$. De no prosperar entonces la propuesta explicada del Proyecto, en la práctica la regla general y legal de distribución será la que se señala en

del que resulta beneficiado con el hecho que ha de probarse, o cómo mínimo dando un poder al juez para imponerle a la parte contraria el deber de colaborar con la aportación de prueba que posea para que la aporte en su propio perjuicio? Entonces, con ello se estaría concediendo una autorización al juez para proceder a imponerle al demandado, por ejemplo, una conducta probatoria a favor de la contraria y en su propio perjuicio, por razones semejantes o parcialmente convergentes con aquellas que se pueden vislumbrar en algún supuesto legal de las denominadas medidas prejudiciales probatorias, como las de los números 3 y 4 del artículo 273 del CPC en vigor. Con todo, esto que puede parecer sumamente arriesgado sin un estudio cabal y la debida regulación, no afecta ni tiene que ver con la carga material de la prueba, puesto que el hecho sigue estando -en principio- necesitado de prueba, y la insuficiencia probatoria sigue afectando al sujeto que ha afirmado el hecho. Salvo, claro está, que al mismo tiempo de dotar al juez con el poder de imponerle la colaboración probatoria a la contraria respecto de un hecho que puede perjudicarle, además se contemple como sanción que la no aportación culposa o dolosa de la prueba acabe con el establecimiento del hecho, sin embargo, realmente no probado.

Estas arduas cuestiones de técnica procesal desde luego no pueden despacharse en un inciso dentro de un artículo, además, confuso e impreciso. Ciertamente un régimen como este entraña riesgos de excesos de todo tipo. Véase, la exposición de PRÜTTING (2006), pp. 59-78, respecto de los parágrafos 142, 144 y 643 de la Ordenanza Procesal Civil alemana. 
el Proyecto en su art. 294, al indicar que "[c]orresponde la carga de probar los fundamentos de hecho contenidos en la norma jurídica a la parte cuya aplicación beneficie, salvo que una disposición legal expresa distribuya con criterios diferentes o de una manera diversa la carga de probar los hechos relevantes entre las partes". En consecuencia la carga de la prueba estará establecida por una norma legal, norma reguladora de la prueba, la cual no es modificable por el propio juez, sino únicamente -como apunta el mismo precepto- por otra norma reguladora que establezca una regla legal especial respecto de la antes mencionada.

Pero en uno u otro supuesto aquellas operan como leyes reguladoras y en tanto cuales ellas pueden ser infringidas por el juzgador del mismo modo que hasta ahora, con lo cual en este punto se mantendría en idénticos términos la pertinencia recursiva de la infracción de las normas legales reguladoras de la carga de la prueba ${ }^{75}$.

\section{Conclusiones}

Consideramos que en el curso del trabajo ha quedado clara la necesidad de desarrollar una interpretación dogmática actualizada del motivo de casación en el fondo, de modo de ofrecer una cobertura casacional que guarde correspondencia con el fin nomofiláctico de defensa del Derecho positivo, que no se ciñe únicamente a la ley o a las denominadas fuentes formales con rango de ley. Para eso se ha propiciado un análisis específico y particularizado, que evita incurrir en la tentación simplificadora y generalizante de esgrimir coberturas casacionales ilimitadas o sin matices técnicos.

En segundo término, en el estudio hemos tomado posición sobre las concretas hipótesis recursivas que plantean dudas acerca de la posibilidad de incardinación casacional, justificando en qué medida y con qué límites se puede promover una interpretación legal (del artículo 767 CPC) que permita darles cobertura casacional, por ejemplo, a la infracción de las normas constitucionales o bien a las infracciones de normas infralegales.

Por otra parte, se ha tomado una posición precisa sobre el argumento frecuente de la relevancia casacional de la infracción de la doctrina jurisprudencial (o del precedente), atendido el actual sistema en vigor que en principio no la contempla como supuesto integrado en el motivo de casación, y desde esa

\footnotetext{
75 En la jurisprudencia de la Corte Suprema no es infrecuente encontrar casos de infracción de normas reguladoras sobre la carga legal probatoria, que acaban dando lugar a la casación de la sentencia de mérito. Así por ejemplo en el último tiempo SCS, rol 6783-2008, de 7 de diciembre de 2009, Legal Publishing CL/JUR/4502/2009; SCS, rol 8005-2011, de 17 de enero de 2012, Legal Publishing CL/ JUR/124/2012.
} 
perspectiva hemos apuntado en qué medida aquello puede ser encarado en una futura reforma procesal civil.

El estudio así mismo ha analizado la propuesta de recurso extraordinario contenida en el Proyecto de Código Procesal Civil, con la finalidad de contrastar esa regulación con la necesidad de contar con una modelación de un motivo del recurso de casación (o del recurso de naturaleza casacional que tome su lugar), y se han puesto de relieve diversas imprevisiones normativas que requieren ser solventadas en la tramitación legislativa pendiente, de modo que la reforma que se pretenda aprobar suponga un auténtico progreso legislativo que se traduzca en un futuro mejor funcionamiento de un instituto procesal tan relevante como el recurso destinado a dar acceso al tribunal supremo encargado de la defensa del derecho objetivo y, por otra parte, de asegurar un razonable grado de unificación jurisprudencial (sincrónica), sin perder de vista que aquello se hace en un sistema jurídico de derecho legislado (positivo y no jurisprudencial).

\section{Bibliografía CitADA}

Aguirrezábal Grünstein, Maite; Baraona González, Jorge y Romero Seguel, Alejandro (2008): "Revisión crítica de la causal fundante del recurso de casación en el fondo en materia civil", en: lus et Praxis (Año 14, $\mathrm{N}^{0} 1$ ), pp. 225-259.

Atria Lemaitre, Fernando (2005): "Proceso civil. Comentario a la jurisprudencia del año 2004", en: Revista de Derecho UAI (№ 2), pp. 249-353.

Bankowski, Zenon, MacCormick, D. N. y Marshall, G. (1997): "Precedent in the United Kingdom", en: A.A.V.V., editado por MacCormick, Neil y Summers, Robert, Interpreting Precedents (Farnham, Ashgate), pp. 315-354.

Baraona VILAR, Silvia, et al. (2000): Derecho Jurisdiccional I, Parte General (10 Edición, Valencia, Tirant Lo Blanch).

Belletti, Michele; D'Orlando, Elena; Feriol, Elena y Mezzetti, Luca (2007): La giustizia costituzionale (Padova, Cedam).

Bellido Penadés, Rafael (2013): El recurso extraordinario por infracción procesal (Madrid, La Ley-WoltersKluwer).

Bellido Penadés, Rafael (2014): El recurso de casación civil (Madrid, La Ley-WoltersKluwer).

BORÉ, Jacque (1988): La cassation en materia civile (París, Sirey).

Calamandreı, Piero (1945): La casación civil (Traducc. Sentís Melendo y Alcalá Zamora y Castillo, Buenos Aires, Editorial Bibliográfica Argentina).

CARnelutti, Francesco (1959): Instituciones del proceso civil (traducción Sentís Melendo, Buenos Aires, EJEA). 
Corral TalCianı, Hernán (2012): "Sobre la carga de la prueba en el Proyecto de Código Procesal Civil", en: Cuadernos de Extensión Jurídica Universidad de Los Andes ( No 23), pp. 107-117.

Couchez, Gérard y Lagarde, Xavier (2014): Procédure civile, $17^{a}$ edición (París, Sirey).

Delgado Castro, Jordi (2012): "El recurso extraordinario en el proyecto de Código Procesal Civil", en: Revista lus et Praxis (Año 18, № 2), pp. 125-146.

Del Río Ferrettı, Carlos (2012): "Función y finalidad de los recursos de naturaleza casacional: conceptos útiles para el diseño del nuevo Código Procesal Civil", en Cuadernos de Extensión Jurídica № 23, Universidad de los Andes, pp. 271-283.

Domínguez Hidalgo, Carmen (2013): "La introducción de las cargas probatorias dinámicas en el derecho chileno", en: A.A.V.V., Estudios de Derecho civil IX (Santiago de Chile, Thomson Reuters).

Echeverría Reyes, Aníbal y Toro Melo, David (1902): Código de Procedimiento Civil anotado (Santiago de Chile, Imprenta, litografía y Encuadernación Barcelona).

Espinosa Solís de Ovando, Alejandro: De los recursos procesales en el Código de Procedimiento Civil (Santiago de Chile, Editorial Nascimento).

Falcón y Tella, María José (2005): Equidad, Derecho y Justicia (Madrid, Editorial Universitaria Ramón Areces).

Fernández González, Miguel Ángel (1993): “La inaplicabilidad del Decreto Ley № 2695 y derogación tácita", en: Revista de Derecho Universidad Austral (Vol. IV), pp. 55-56.

Fernández GonzÁlez, Miguel Ángel (2001): "La fuerza normativa de la Constitución", en: Revista de Derecho Público (Vol. 63), pp. 77-102.

Fernández González, Miguel Ángel (2005): “Constitución y casación: "¿De la falta de aplicación al monopolio constitucional", en: Revista del Centro de Estudios Constitucionales (Año 3, Nº 1), pp. 97-118.

FerNÁNDEZ Richard, José (2000): “Infracción a una norma reglamentaria de la ley general de urbanismo y construcciones, no puede ser atacada por la vía del recurso de casación", en: Gaceta Jurídica (№ 236), pp. 153-154.

González Coulón, María de los Ángeles (2013): La carga dinámica de la prueba y sus límites (Santiago, Thomson Reuters).

Lagarde, Xavier y Couchez, Gérard (2014): Procédure civile, $17^{\text {a }}$ edición (París, Sirey). 
LARROCAU TORRES, Jorge (2014): “¿Cómo se prueba la responsabilidad civil médica en la justicia chilena?", en: Revista de Derecho, UACh (V. XXVII, № 2), pp. 65-72.

Letelier WartenberG, Raúl (2007): "Jueces ordinarios y justicia constitucional", en: Revista chilena de Derecho (Vol. 34, № 3), pp. 539-574.

Maturana, Cristián y Mosquera, Mario (2010): Los recursos procesales (Santiago, Editorial Jurídica de Chile).

Michel, Gian Antonio (1961): La carga de la prueba (Traducc. SentisMelendo, Buenos Aires, Ejea).

Morón Palomino, Manuel (1998): "El recurso de casación civil y su reforma", en: Diario La Ley, ref. D-177, tomo III.

Morón Palomino, Manuel (2001): La nueva casación civil (Madrid, Colex).

Muñoz Gajardo, Sergio (2008): "Uniformidad de jurisprudencia. Informe", rol AD (asunto administrativo) 168-2008, inédito.

Muñoz Gajardo, Sergio (2010): "Presente y futuro de la casación civil en Chile", en: Derecho procesal contemporáneo (Coordinador Tavolari Oliveros, Santiago de Chile, Thomson Reuters), tomo I.

NAPPI, Aniello (2006): Il sindacato di legittimità nei giudizi civili e penali di cassazione (Torino, Giappichelli Editore).

Nieva Fenoll, Jordi (2010): El recurso de casación (Santiago de Chile, Editorial AbeledoPerrot).

Ortells Ramos, Manuel; Mascarell Navarro, María José; Cámara Ruiz, Juan; Juan Sánchez, Ricardo; Bonet Navarro, José; Bellido Penadés, Rafael; Cucarella Galiana, Luis Andrés y Martín PAstor, José (2010): Derecho procesal civil (Navarra, AranZadi).

Palltás, Enrique (2008): El recurso de casación en materia civil: Derecho chileno y comparado (Santiago, Editorial Jurídica de Chile).

PRÜTTING, Hanns (2006): "Presentación de documentos y dirección del proceso", en: Código Procesal Civil alemán (Traducc. Ortiz Pradillo y Pérez Ragone (Montevideo, Fundación Konrad Adenauer), pp. 59-78.

Serra Domínguez, Manuel (1993): "El recurso de casación", en: La reforma de los procesos civiles (Madrid, Civitas).

Summers, Robert (1997): "Precedent in the United State (New York State)", en: A.A.V.V., Interpreting Precedents (Farnham, Ashgate), pp. 355-406.

Toro Melo, David y Echeverría Reyes, Aníbal (1902): Código de Procedimiento Civil anotado (Santiago de Chile Imprenta, litografía y Encuadernación Barcelona). 
VÁzquez Sotelo, José Luis (1979): La casación civil (revisión crítica) (Barcelona, Ediser).

Walter, Gerhard (2001): "I diritti fondamentali nel processo civile tedesco", en: Rivista di Diritto Processuale (LVI, No 3), pp. 733-749.

ZúNíIGA URBINA, Francisco (2005): "Control de constitucionalidad y casación", en: Revista del Centro de Estudios Constitucionales (Año 3, № 2), pp. 15-27.

\section{JURISPRUDENCIA CITADA}

Banco de Crédito e Inversiones con Hurtado, Corte Suprema, 7 de diciembre de 2009, rol 6783-2008, Legal Publishing CL/JUR/4502/2009.

Centro de Diálisis Renca Ltda. con Riquelme, Corte Suprema, 7 de octubre de 2010, rol 4118-2010, Legal Publishing CL/JUR/8069/2010.

Copec S.A. con Spencer e hijo Ltda., Corte Suprema, 13 de octubre de 2010, rol 2281-2010, Legal Publishing CL/JUR/8194/2010.

Corredores de Propiedades Vidal Ltda. con Inmobiliaria Las Encinas Ltda., Corte Suprema, 12 de agosto de 2011, rol 6661-2009, Legal Publishing CL/JUR/6510/2011.

Fisco de Chile con Importadora y Exportadora Bendell S.A., Corte Suprema, 20 de marzo de 2013, rol 11908-2011, Legal Publishing CL/JUR/618/2013.

Orden de la Compañía de María N.S. con Alcalde de Providencia, Corte Suprema, 6 de diciembre de 1999, rol 2771-99.

Penta Vida Compañía de Seguros S.A. con Salinas, Corte Suprema, 17 de enero de 2012, rol 8005-2011, Legal Publishing CL/JUR/124/2012.

Perry con Ceballos, Corte Suprema, 6 de julio de 2011, rol 5037-2011, Legal Publishing CL/JUR/5429/2011.

San Martín con Servicio de Salud Ñuble, Corte Suprema, 26 de octubre de 2010, rol 4994-2008, Legal Publishing CL/JUR/8802/2010.

Servicom Talcahuano Ltda. con Empresa Constructora Tecsa S.A., Corte Suprema, 30 de noviembre de 2012, rol 7803-12, Legal Publishing CL/JUR/2762/2012.

Sociedad doctor Manuel Díaz y Cía. Ltda. con Servicio de Impuestos Internos, Corte Suprema 4 de enero de 2001, RDJ, t. 98, sec. $1^{\text {a }}$.

Soria con Servicio de Impuestos Internos, Corte Suprema, 15 de diciembre de 2009, rol 1343-2008, Legal Publishing CL/JUR/4841/2009.

Superior FruitService S.A. con Oceánica S.A., Corte Suprema, 4 de mayo de 2011, rol 7535-2009, Legal Publishing CL/JUR/9689/2011. 